\title{
Patterns of Diversity of Floral Symmetry in Angiosperms: A Case Study of the Order Apiales
}

\author{
Maxim S. Nuraliev ${ }^{1,2, * \mathbb{D}}$, Dmitry D. Sokoloff ${ }^{1}$, Polina V. Karpunina ${ }^{1}$ and Alexei A. Oskolski ${ }^{3,4}$ \\ 1 Faculty of Biology, Lomonosov Moscow State University, 119234 Moscow, Russia; \\ sokoloff-v@yandex.ru (D.D.S.); p.karpunina@yandex.ru (P.V.K.) \\ 2 Joint Russian-Vietnamese Tropical Scientific and Technological Center, Hanoi 10000, Vietnam \\ 3 Department of Botany and Plant Biotechnology, University of Johannesburg, P.O. Box 524, Auckland Park \\ 2006, Johannesburg, South Africa; aoskolski@gmail.com \\ 4 Botanical Museum, V.L. Komarov Botanical Institute, 197376 St. Petersburg, Russia \\ * Correspondence: max.nuraliev@gmail.com; Tel.: +7-495-9391827
}

Received: 16 March 2019; Accepted: 30 March 2019; Published: 3 April 2019

check for updates

\begin{abstract}
Floral symmetry is widely known as one of the most important structural traits of reproductive organs in angiosperms. It is tightly related to the shape and arrangement of floral parts, and at the same time, it plays a key role in general appearance (visual gestalt) of a flower, which is especially important for the interactions of zoophilous flowers with their pollinators. The traditional classification of floral symmetry divides nearly all the diversity of angiosperm flowers into actinomorphic and zygomorphic ones. Within this system, which is useful for ecological studies, many variations of symmetry appear to be disregarded. At the same time, the diversity of floral symmetry is underpinned not only by ecological factors, but also by morphogenetic mechanisms and constraints. Sometimes it is not an easy task to uncover the adaptive or developmental significance of a change of the floral symmetry in a particular lineage. Using the asterid order Apiales as a model group, we demonstrate that such changes can correlate with the merism of the entire flower or of its particular whorl, with the relative orientation of gynoecium to the rest of the flower, with the presence of sterile floral elements and other morphological characters. Besides, in some taxa, the shape and symmetry of the flower change in the course of its development, which should be taken in consideration in morphological comparisons and evaluations of synapomorphies in a particular clade. Finally, we show that different results can be obtained due to employment of different approaches: for instance, many flowers that are traditionally described as actinomorphic turn out to be disymmetric, monosymmetric, or asymmetric from a more detailed look. The traditional method of division into actinomorphy and zygomorphy deals with the general appearance of a flower, and mainly considers the shape of the corolla, while the geometrical approach handles the entire three-dimensional structure of the flower, and provides an exact number of its symmetry planes.
\end{abstract}

Keywords: Apiaceae; Araliaceae; asymmetry; development; evolution; flower; merism; monosymmetry; Umbelliferae

\section{Introduction}

Apiales is an order of campanulid asterids comprising seven families [1], which considerably differ from each other in flower groundplan and the range of its variation. For this reason, Apiales are an excellent model group for studies of the diversity of floral shape, including symmetry, and for the questions of its interrelations with other features of flower morphology.

The majority of species diversity of Apiales is confined to two families, i.e., Apiaceae and Araliaceae, which are both characterized by the predominance of zoophily. Flowers of Apiaceae 
are rather uniform in their appearance and the number of floral elements (which are shared between Apiaceae and their closest relatives, Myodocarpaceae). Araliaceae, in contrast, show a considerable variation in certain features of flower structure, which are commonly constant or almost so in many other euasterid families. These features include the number of whorls and their merism, and the presence of calyx and corolla tubes [2,3]. Most of these traits have direct or indirect influences on the symmetry of the entire flower, or its particular whorl. The rest of the families of Apiales contribute to the diversity of flowers of the order by showing several peculiar floral types, such as hypogynous flowers with variable carpel number in Pittosporaceae [4], and flowers with pseudomonomerous gynoecia of various morphology in Griseliniaceae, Pennantiaceae, and Torricelliaceae $[5,6]$. The data on flower structure in some members of Apiales question several commonly accepted ideas on the classification of the symmetry of angiosperm flowers.

In this paper, we present an overview of the types of floral symmetry in Apiales, and we discuss correlations between the patterns of floral symmetry, and other characters of floral structure and development. This overview is based on our extensive studies on the floral morphology of Apiales, and also on the publications that are cited in text. We also consider some terminological issues, including the differences in existing approaches for symmetry determination.

\section{Background: The Concepts of Floral Actinomorphy and Zygomorphy from Geometrical and Ecological Viewpoints}

The symmetry of flowers manifested in the differential shape and/or arrangement of their parts is widely known to be one of the most important structural traits of reproductive organs in angiosperms. Symmetry contributes to the general appearance of a flower, and it represents one of the key components of a plant pollination syndrome. Two major types of floral symmetry, i.e., actinomorphy (radial symmetry) and zygomorphy (bilateral symmetry), are traditionally recognized in botany. The former type is commonly considered to be a synonym of polysymmetry, i.e., the kind of floral symmetry with more than two planes, while the latter type is synonymized with monosymmetry, i.e., the condition with a single symmetry plane [7-16]. Although the terms "actinomorphy" and "zygomorphy" are aimed to divide the diversity of floral shape into two contrasting and easily recognizable groups, they are structurally imprecise, as they lack any strict criteria. Moreover, these two terms do not cover the cases of presence of two different (i.e., dividing in different ways) symmetry planes in a flower or the absence of any planes (disymmetry and asymmetry: [9-11]). In the literature on the genetics of floral development, e.g., [17-19], zygomorphic (monosymmetric) flowers are often confused with asymmetric ones, which is geometrically incorrect [11].

In most cases, a flower is assumed to be actinomorphic if it possesses a polysymmetric corolla (or any other visually prominent part), while the symmetry of other floral whorls remains out of consideration $[7,12,14,15,20]$. Within this approach, a planar projection of the flower in a top view (en face) is usually analyzed, and only rarely its three-dimensional structure [12]. For this reason, it is common to speak of axes of symmetry, though the establishment of planes of symmetry is more appropriate [15]. On the other hand, the classification of floral symmetry reflecting all the details of its three-dimensional structure is "complex and unwieldy, and simple definitions of flower types are generally preferred" [15] (p. 88), though they do not always reflect the peculiarities of the interactions of the flower with a pollinator. The terms "actinomorphy" and "zygomorphy" appear to be more ecological rather than structural ones: they distinguish flowers in which the position of an animal pollinator is strictly defined (as well as the flowers of pseudanthial inflorescences imitating petals), i.e., the zygomorphic ones, from all the other, i.e., actinomorphic, flowers [7,21]. Moreover, floral symmetry plays an important role in the visual perception of flower by a pollinator $[7,9,13,22-24]$. Obviously, in this case, only the structure of the most conspicuous floral parts is significant; besides, the number of symmetry types distinguished by these animals cannot be high. Particularly, the insects were shown to be able to distinguish symmetrical vs asymmetrical flowers, and bilateral vs radial ones [22,23]. 
Among the attempts to develop a comprehensive classification of types of floral symmetry, the works by Leppik $[25,26]$ merit special attention. He distinguished five main "type classes" of flowers: (1) amorphic, characterized by discolored organs and the absence of a definite form of symmetry, (2) haplomorphic, characterized by a hemispheric perianth of numerous elements, (3) actinomorphic, characterized by radial symmetry and a more or less flat flower, (4) stereomorphic, characterized by a pronounced three-dimensional structure with stamens and nectar hidden in the flower depth, and (5) zygomorphic, characterized by bilateral symmetry that is distinguished by the pollinators. Leppik assumed these classes to be associated not only with the symmetry itself, but also with floral color, the number of floral organs, the spatial arrangement of floral parts, and the patterns of interaction of the flower with its pollinators. Leppik's classification is thus detailed and elaborate, as it considers not only the general appearance of the flower, but also the particular structural features. However, the employment of such heterogeneous features within the limits of a small number of types has made this classification quite complicated and contradictory. As a result, it has never been widely adopted.

\section{Materials and Methods}

This is mainly a literature review. In addition, the following material was used to produce the illustrations.

Schefflera membranifolia Bui, Figure 1A: Northern Vietnam, Lao Cai province, Sa Pa district, San Sa Ho municipality, Hoang Lien National Park, Tram Ton area, near river, 10.07.2009, Nuraliev M.S. 36 (MW: spirit collection).

Schefflera trevesioides Harms, Figure 1B: Northern Vietnam, Lao Cai province, Sa Pa district, San Sa Ho municipality, Hoang Lien National Park, Cat Cat village area, near trail to road, along main stream, N 22 $20^{\prime} 00^{\prime \prime} \mathrm{E} 103^{\circ} 49^{\prime} 30^{\prime \prime}, 1300 \mathrm{~m}$ above sea level (a.s.1.), 17.12.2009, Nuraliev M.S. 53 (MW: MW0743213, MW0743214, MW0743219, MW0743220).

Pittosporum balansae A.DC., Figure 1D: Southern Vietnam, Dak Lak province, Lak district, Bong Krang municipality, Chu Yang Sin National Park, $10 \mathrm{~km} \mathrm{~S}$ of Krong Kmar village, forest, near river, N $12^{\circ} 24^{\prime} 55^{\prime \prime}$ E $108^{\circ} 21^{\prime} 05^{\prime \prime}, 900$ m a.s.1., 22.03.2013, Nuraliev M.S., Kuznetsov A.N., Kuznetsova S.P. 688 (MW: MW0750232).

Schefflera actinophylla (Endl.) Harms, Figure 2A-E: China, Shenzhen, cultivated in the Fairy Lake Botanical Gardens, 27.09.2005, Oskolski A.A. s.n. (MW: spirit collection) and South Africa, Johannesburg, cultivated on the campus of the University of Johannesburg, 12.05.2007, Oskolski A.A. s.n. (MW: spirit collection); Figure 2F: Cyprus, Paphos, cultivated, N $34^{\circ} 44^{\prime} 46^{\prime \prime}$ E $32^{\circ} 25^{\prime} 44^{\prime \prime}, 10 \mathrm{~m}$ a.s.l., 16.01.2017, Sokoloff D.D. s.n. (MW: spirit collection).

Polyscias duplicata (Thouars ex Baill.) Lowry \& G.M.Plunkett, Figure 3A-C: Northern Madagascar, Antsiranana province, Sava Region, Andapa district, near Marojejy National Park, $26 \mathrm{~km}$ NE of Andapa town, Park visitor center, disturbed area, S 14 $29^{\prime} 48^{\prime \prime}$ E 49 $49^{\prime} 24^{\prime \prime}, 60$ m a.s.l., 19.10.2015, Karpunina P.D., Nuraliev M.S., Oskolski A.A., Ravelonarivo D., Razafindrahaja V., Tonkaina J.H. PK 267 (MW, P, TAN); Figure 3D: Northern Madagascar, Antsiranana province, Sava Region, Andapa district, Marojejy National Park, $28 \mathrm{~km}$ NNE of Andapa town, Camp. 2 (Marojejia) area, near trail, dense montane rainforest, river bank, $\mathrm{S} 14^{\circ} 26^{\prime} 06^{\prime \prime} \mathrm{E} 49^{\circ} 45^{\prime} 39^{\prime \prime}, 780 \mathrm{~m}$ a.s.l., 15.10.2015, Karpunina P.D., Nuraliev M.S., Oskolski A.A., Ravelonarivo D., Razafindrahaja V., Tonkaina J.H. PK 209 (MW: MW0582499, P, TAN).

Tupidanthus calyptratus Hook.f. \& Thomson, Figure 4A: USA, California, San Diego, cultivated, May-September 2003, Kudryavtseva E.I. s.n. (MW: spirit collection); Figure 4B: Russia, Moscow, cultivated in the greenhouse of the Russian State Agrarian University-Moscow Timiryazev Agricultural Academy, 17.02.2015; Figure 4C: same plant, 20.02.2015; Figure 4D: Australia, Sydney, cultivated in the Royal Botanic Garden Sydney, 02.08.2011.

Hydrocotyle nepalensis Hook., Figure 5A: Northern Vietnam, Cao Bang province, Nguyen Binh district, Phia Oac-Phia Den National Park, 11 km WSW of Nguyen Binh town, Phia Oac summit area, wet foggy mossy crooked forest with bamboo on slope, N 22 $36^{\prime} 58^{\prime \prime}$ E $105^{\circ} 51^{\prime} 49^{\prime \prime}, 1900 \mathrm{~m}$ a.s.l., 03.10.2018, Nuraliev M.S. 2232 (MW). 
Thyselium palustre (L.) Raf., Figure 5B: Russia, St. Petersburg, Yuntolovskiy National Wildlife Reserve, 11.07.2011, Nuraliev M.S. s.n. (MW: MW-DigiPic0000015).

Tordylium aegyptiacum (L.) Poir., Figure 5D: Cyprus, Limassol area, around N 34 $42^{\prime} 45^{\prime \prime}$ E $33^{\circ} 08^{\prime} 20^{\prime \prime}$, 20 m a.s.l., 22.03.2011, Nuraliev M.S. s.n. (MW: MW-DigiPic0000016).

Photographs of living plants were taken by M.S. Nuraliev with a Pentax Optio W80 (Pentax Corporation, Tokyo, Japan) digital camera. All of the images were treated using PHOTOSHOP ELEMENTS (Adobe Systems, San Jose, CA, USA). One scanning electron microscopy (SEM) image was colored using CORELDRAW X5 (Corel Corporation, Ottawa, Canada). Floral diagrams were prepared using Inkscape, version 0.92 (www.inkscape.org).

For SEM, the flowers were fixed and stored in 70\% ethanol, dehydrated in $96 \%$ ethanol followed by $100 \%$ acetone. Dehydrated material was critical-point dried using a HCP-2 critical point dryer (Hitachi, Tokyo, Japan), coated with gold and palladium using an Eiko IB-3 ion-coater (Eiko Engineering Co. Ltd., Tokyo, Japan), and observed by using a CamScan 4 DV (CamScan, Cambridge, UK) SEM at Moscow State University.

\section{Results}

All major types of floral symmetry are found in Apiales. These types correlate with the number of floral elements in each floral whorl, and patterns of organ arrangement. Detailed data on the diversity of the symmetry of floral whorls, as well as the receptacle, are summarized in Table 1 . The differences in the symmetry of particular flowers and their whorls are related to interactions between the outlines of floral parts, the merism of whorls, and the patterns of their arrangement. Some of the combinations of features are listed as co-occurring in the same species, representing intraspecific variation or different developmental stages.

Table 1. Diversity of the floral symmetry in Apiales.

\begin{tabular}{|c|c|c|c|}
\hline Notation & Floral Formula & Important Features & Examples of Taxa and References \\
\hline P1 & $\mathrm{R}^{*} \mathrm{Kn} \mathrm{n}^{*} \leftrightarrow \mathrm{Cn} * \leftrightarrow \mathrm{An} * \leftrightarrow \mathrm{Gn} *$ & $\begin{array}{l}\text { Isomerous (mainly pentamerous) whorls, } \\
\text { stable orientation of the gynoecium }\end{array}$ & $\begin{array}{c}\text { Araliaceae: Aralia, Hedera [27], some } \\
\text { Plerandra subg. Canacoschefflera (pers. } \\
\text { obervations), some Asian Schefflera, } \\
\text { Schefflera actinophylla (early stages) } \\
{[2,3,28,29]}\end{array}$ \\
\hline $\mathrm{P} 2$ & $\mathrm{R}^{*} \mathrm{Kn} * \leftrightarrow \mathrm{Cn} * \leftrightarrow \mathrm{A} \infty * \mathrm{Gn} *$ & $\begin{array}{c}\text { Isomerous (mainly pentamerous) perianth } \\
\text { whorls and gynoecium, polymerous } \\
\text { androecium, stable orientation of } \\
\text { gynoecium }\end{array}$ & $\begin{array}{l}\text { Araliaceae: some Plerandra subg. Plerandra, } \\
\text { some Polyscias subg. Tetraplasandra [2] }\end{array}$ \\
\hline P3 & $\mathrm{R}^{*} \mathrm{Kn}{ }^{*} \leftrightarrow \mathrm{Cn} * \mathrm{~A} \infty{ }^{*} \mathrm{G} \infty *$ & $\begin{array}{l}\text { Isomerous (mainly pentamerous) perianth, } \\
\text { polymerous androecium and gynoecium }\end{array}$ & $\begin{array}{l}\text { Araliaceae: some Plerandra subg. Plerandra } \\
\text { (pers. observations) }\end{array}$ \\
\hline D1 & $\mathrm{R}^{*} \mathrm{~K} 4 * \leftrightarrow \mathrm{C} 4 * \leftrightarrow \mathrm{A} 4 * \leftrightarrow \mathrm{G} 2 \dagger$ & $\begin{array}{l}\text { Stable orientation of the dimerous } \\
\text { gynoecium, superimposed with } \\
\text { tetramerous other whorls }\end{array}$ & Araliaceae: Tetrapanax (pers. observations) \\
\hline D4 & $\mathrm{R} * \mathrm{Kn} * \leftrightarrow \mathrm{Cn} * \leftrightarrow \mathrm{A} \infty * \mathrm{G} \infty+$ & $\begin{array}{c}\text { P3 + disymmetric gynoecium with two } \\
\text { rows of carpels (at least in the } \\
\text { symplicate zone) }\end{array}$ & $\begin{array}{l}\text { Araliaceae: certain Plerandra subg. } \\
\text { Plerandra [2] }\end{array}$ \\
\hline M1 & $\mathrm{R} * \mathrm{~K} 5 * \leftrightarrow \mathrm{C} 5 * \leftrightarrow \mathrm{A} 5 * \leftrightarrow \mathrm{G} 2 \dagger$ & $\begin{array}{l}\text { Stable median orientation of a dimerous } \\
\text { gynoecium superimposed with other } \\
\text { pentamerous whorls }\end{array}$ & $\begin{array}{c}\text { Most Apiaceae [29,33-35], } \\
\text { Araliaceae: Cussonia, Harmsiopanax, } \\
\text { Polyscias elegans, Polyscias subg. Polyscias } \\
\text { [30,36], Raukaua [37], Seemannaralia [38], } \\
\text { Myodocarpaceae [39] }\end{array}$ \\
\hline M2 & $\mathrm{R} * \mathrm{~K} 5 * \leftrightarrow \mathrm{C} 5 \downarrow \leftrightarrow \mathrm{A} 5 * \leftrightarrow \mathrm{G} 2 \dagger$ & M1 + monosymmetric corolla & $\begin{array}{c}\text { Apiaceae: Ammi, Artedia, Coriandrum, } \\
\text { Daucus, certain Heracleum, Orlaya, } \\
\text { Ormosciadium, Tordylium [40] (and pers. } \\
\text { observations), } \\
\text { Araliaceae: Trachymene pilosa [41] }\end{array}$ \\
\hline
\end{tabular}


Table 1. Cont.

\begin{tabular}{|c|c|c|c|}
\hline Notation & Floral Formula & Important Features & Examples of Taxa and References \\
\hline M3 & $\mathrm{R} * \mathrm{~K} 5 * \leftrightarrow \mathrm{C} 5 * \leftrightarrow \mathrm{A} 5 * \leftrightarrow \mathrm{G} 2 \downarrow$ & $\begin{array}{l}\text { M1 + monosymmetric heterocarpellate } \\
\text { gynoecium }\end{array}$ & $\begin{array}{c}\text { Apiaceae: Actinotus, Arctopus, Heteromorpha, } \\
\text { Lagoecia, Petagnaea, Pollemanniopsis, } \\
\text { Steganotaenia }[34,42-44]\end{array}$ \\
\hline M4 & $\mathrm{R}^{*} \mathrm{Kn}{ }^{*} \leftrightarrow \mathrm{Cn} * \leftrightarrow \mathrm{An}^{*} \leftrightarrow \approx \mathrm{Gn}^{\prime} \varnothing$ & $\begin{array}{l}\text { Variable orientation of a monosymmetric } \\
\text { gynoecium (occasional coincidence of its } \\
\text { symmetry plane with those of other whorls) }\end{array}$ & $\begin{array}{l}\text { Araliaceae: Polyscias diversifolia, P. schultzei } \\
\qquad\left(n^{\prime}=1\right)[45]\end{array}$ \\
\hline M6 & $\mathrm{R}^{*} \mathrm{~K} 5^{*} \leftrightarrow \mathrm{C} 5^{*} \leftrightarrow \mathrm{A} 5^{*} \leftrightarrow \mathrm{G} 3 \rightarrow$ & $\begin{array}{l}\text { Stable transverse orientation of a } \\
\text { monosymmetric gynoecium }\end{array}$ & Torricelliaceae: Melanophylla [6] \\
\hline M7 & $\begin{aligned} \mathrm{R} \rightarrow \leftrightarrow \mathrm{K} \rightarrow & \leftrightarrow \mathrm{C} \rightarrow \leftrightarrow \mathrm{A} \infty \rightarrow \leftrightarrow \\
& \mathrm{G} \infty \rightarrow\end{aligned}$ & $\begin{array}{l}\text { Monosymmetric outline of the receptacle } \\
\text { and the floral whorls }\end{array}$ & Araliaceae: Tupidanthus calyptratus [32] \\
\hline $\mathrm{A} 3$ & $\mathrm{R} * \mathrm{~K} 5 * \leftrightarrow \mathrm{C} 5$ ל $\mathrm{A} 5$ \ $\mathrm{G} 3 \rightarrow$ & $\begin{array}{l}\text { Contort aestivation with the opposite } \\
\text { direction of the contortion in the corolla } \\
\text { and androecium }\end{array}$ & Torricelliaceae (buds): Melanophylla [6] \\
\hline A4 & $\mathrm{R} * \mathrm{Kn} * \leftrightarrow \mathrm{Cn} * \leftrightarrow \mathrm{An}^{*} \approx \mathrm{Gn}^{\prime} \varnothing$ & $\begin{array}{l}\text { Variable orientation of a monosymmetric } \\
\text { gynoecium }\end{array}$ & $\begin{array}{l}\text { Araliaceae: Polyscias diversifolia and } \\
\text { P. schultzei }\left(\mathrm{n}^{\prime}=1\right)[45]\end{array}$ \\
\hline A5 & $\mathrm{R}^{*} \mathrm{Kn} \mathrm{C}^{*} \leftrightarrow \mathrm{Cn} * \leftrightarrow \mathrm{An}^{*} \approx \mathrm{G} 3 *$ & $\begin{array}{l}\text { Variable orientation of a polysymmetric } \\
\text { gynoecium }\end{array}$ & $\begin{array}{l}\text { Araliaceae: Cheirodendron (pers. } \\
\text { observations), } \\
\text { Pittosporaceae: many Pittosporum [50-52] }\end{array}$ \\
\hline
\end{tabular}

Symbols According to Prenner et al. [57]: K-calyx; C-corolla; A-androecium; G-gynoecium; $\downarrow-$ median monosymmetry; $\rightarrow$ - transverse monosymmetry; $\varnothing$ —oblique monosymmetry; †—disymmetry; ${ }^{*}$-polysymmetry; $\partial$ —asymmetry; Additional Symbols Proposed Here: R—receptacle; n-countable (usually <12) number of organs in a whorl (opposed to "many" organs, designated as $\infty$ ); $\mathrm{n}^{\prime}$ - countable number of organs in a whorl, which is not necessarily equal to the number of organs in other whorls of the same flower; $\leftrightarrow$-coincidence of symmetry planes between whorls (Prenner et al. [57] used this symbol only for whorl(s) of obdiplostemonous and obhaplostemonous androecia); 4 -rotational symmetry (without symmetry planes); $\approx$-variable orientation of a whorl within a plant individual or a species.

The table summarizes the combinations of the symmetry types that are expressed by floral whorls and the receptacle. Unlike the major symmetry types that are accepted in the Results, as many deviations from polysymmetry as possible are recorded here, including some minor ones. Unless otherwise stated, the manifestations of symmetry in anthetic flowers are presented. Notations of the combinations are based on the resulting types of floral symmetry ( $\mathrm{P}$ - polysymmetry, $\mathrm{D}$ - disymmetry, $\mathrm{M}$-monosymmetry, A-asymmetry). Floral formulae were compiled mostly based on the symbols proposed by Prenner et al. [57]. The number of elements in a whorl was not indicated if they could not be distinguished from each other (i.e., the presence of the individual elements was questionable). Fusions between floral organs are not indicated.

Below, we provide a survey of floral groundplans that are characteristic for each of the major types of floral symmetry in Apiales.

\subsection{Polysymmetric Flowers}

Polysymmetry occurs in flowers of two meristic types:

a. Isomerous oligomerous flowers, i.e., those possessing equal and at the same time moderate number of elements in each whorl (Table 1: P1, A1). Tetra-, penta-, and hexamerous flowers of this groundplan are known in Apiales (Figure 1A-C). Within Apiales, in flowers of this groundplan, each 
whorl consists of equal elements, which are evenly arranged; the receptacle shape and the shape of each whorl is round in outline, and the elements of the neighboring whorls alternate with each other. Thus, this groundplan can be assumed as an "ideally" polysymmetric one, as it meets all of the possible criteria of polysymmetry; with regard to the identification of the symmetry type of the flowers with other groundplans, it is useful to compare them with this one. We do not consider the aestivation of the sepals and petals (i.e., the pattern of their overlapping in flower bud [58,59]; Table 1: A1-A3, A6) in the determination of the type of floral symmetry, because otherwise, all of the flowers with closed and non-valvate aestivation of at least one pentamerous whorl cannot be treated as polysymmetric ones, which is apparently impractical (see below). Asymmetry that is caused by other minor or hidden parameters (for example, the relative spacing of the fertile and the sterile ovules in the carpels) is not considered here and in the following sections.

Flowers of this groundplan are found in the family Araliaceae, where it is among the most common ones, and also in certain representatives of Pittosporaceae.
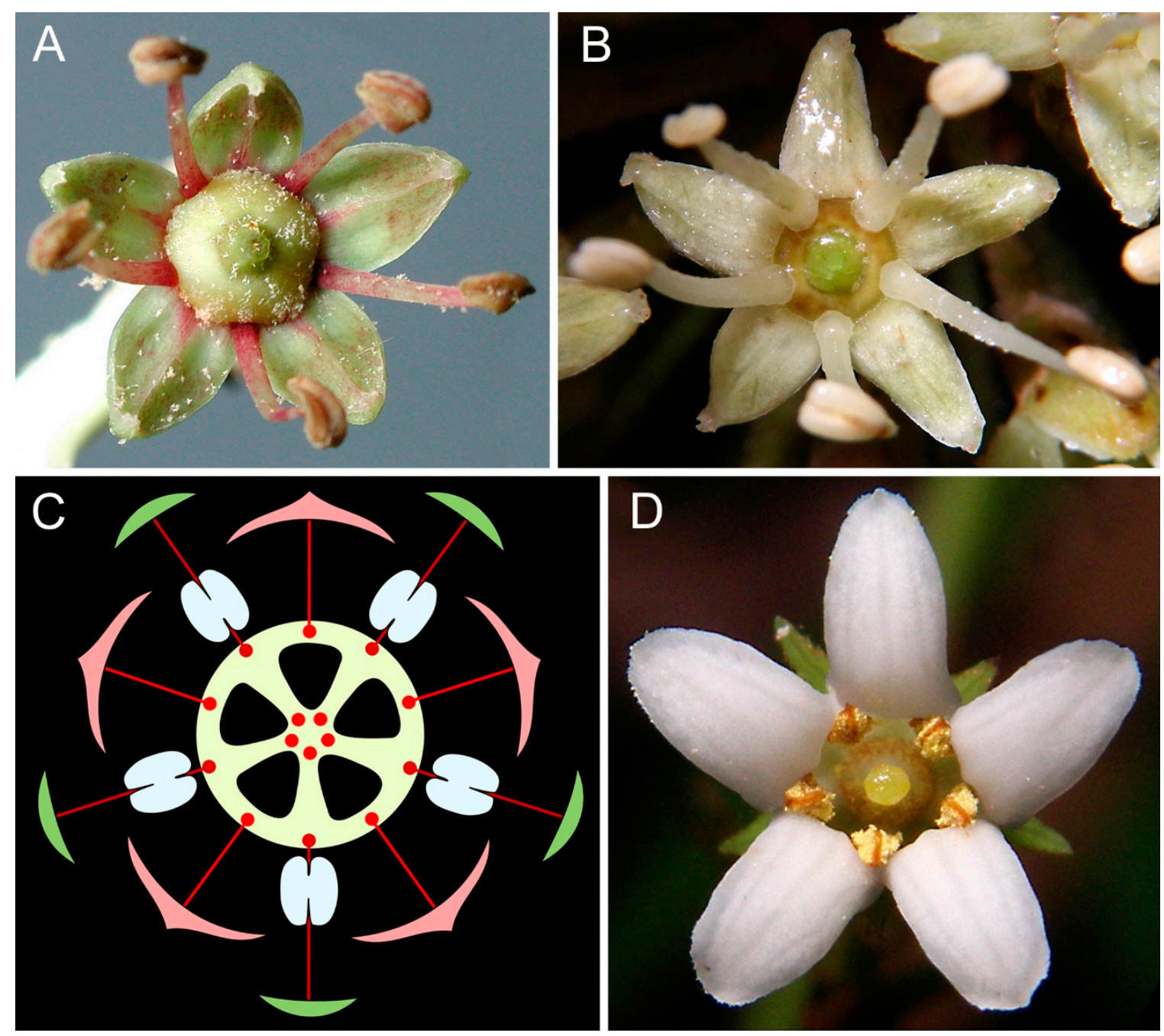

Figure 1. Flowers of Apiales. A,B, Schefflera membranifolia (A) and S. trevesioides (B) (Araliaceae), five elements in each whorl, top view. (C). Generalized diagram of a pentamerous flower of Araliaceae with superimposed main vascular bundles. (D). Pittosporum balansae (Pittosporaceae), with a dimerous gynoecium of unknown orientation and pentamerous other whorls, top view. 
b. Flowers with a polymerous androecium and pentamerous (or nearly so) other whorls (Table 1: P2, also P3 for flowers with more than six carpels). Here and below, we consider a flower or its whorl as being polymerous if its merism is higher than six, because five elements in a whorl is a "basic" (most common and probably ancestral, at least for the perianth and androecium [20]) condition in Apiales, and a merism of six occurs frequently within the limits of the natural variation of many species with normally pentamerous whorls. In this particular case (1b), the number of stamens in a whorl is commonly several times higher than five. This type is similar to the previous one (1a), except for the criterion of whorl alternation, which is not applicable here for the androecium. This type is known in certain Araliaceae, e.g., some species of Plerandra subgen. Plerandra and Polyscias subgen. Tetraplasandra [2].

\subsection{Disymmetric Flowers}

This type is quite rare in Apiales; it is associated with two types of floral merism:

a. Flowers with a dimerous gynoecium and tetramerous other whorls (Table 1: D1). Here, the gynoecium is disymmetric, because it consists of two equal carpels (which are monosymmetric and share the same plane of symmetry), and the other whorls are polysymmetric, with an even (namely, four) number of symmetry planes. As long as the carpels are arranged in the radii of stamens in Apiales with such flowers, each of the two planes of symmetry of the gynoecium coincides with a plane of symmetry for the rest of the flower, which results in a disymmetry in the entire flower. Flowers of this type are found in Tetrapanax (Araliaceae).

b. Isomerous (and hemiisomerous) polymerous flowers, as well as some polymerous flowers with gynoecium merism that is higher than the merism of the other whorls (Table 1: D2-D4). In representatives of Apiales with these groundplans, the floral structure is similar to that of polysymmetric flowers (groundplan 1a) in having each whorl with equal elements, which are evenly arranged; however, it differs from the latter by the non-round outline of some of the whorls, and sometimes also the non-round shape of the receptacle. Species with such flowers are scattered among several lineages of Araliaceae, including the genera Osmoxylon, Polyscias, Schefflera (Asian species group), and Tupidanthus (Figures 2, 3 and 4A). 

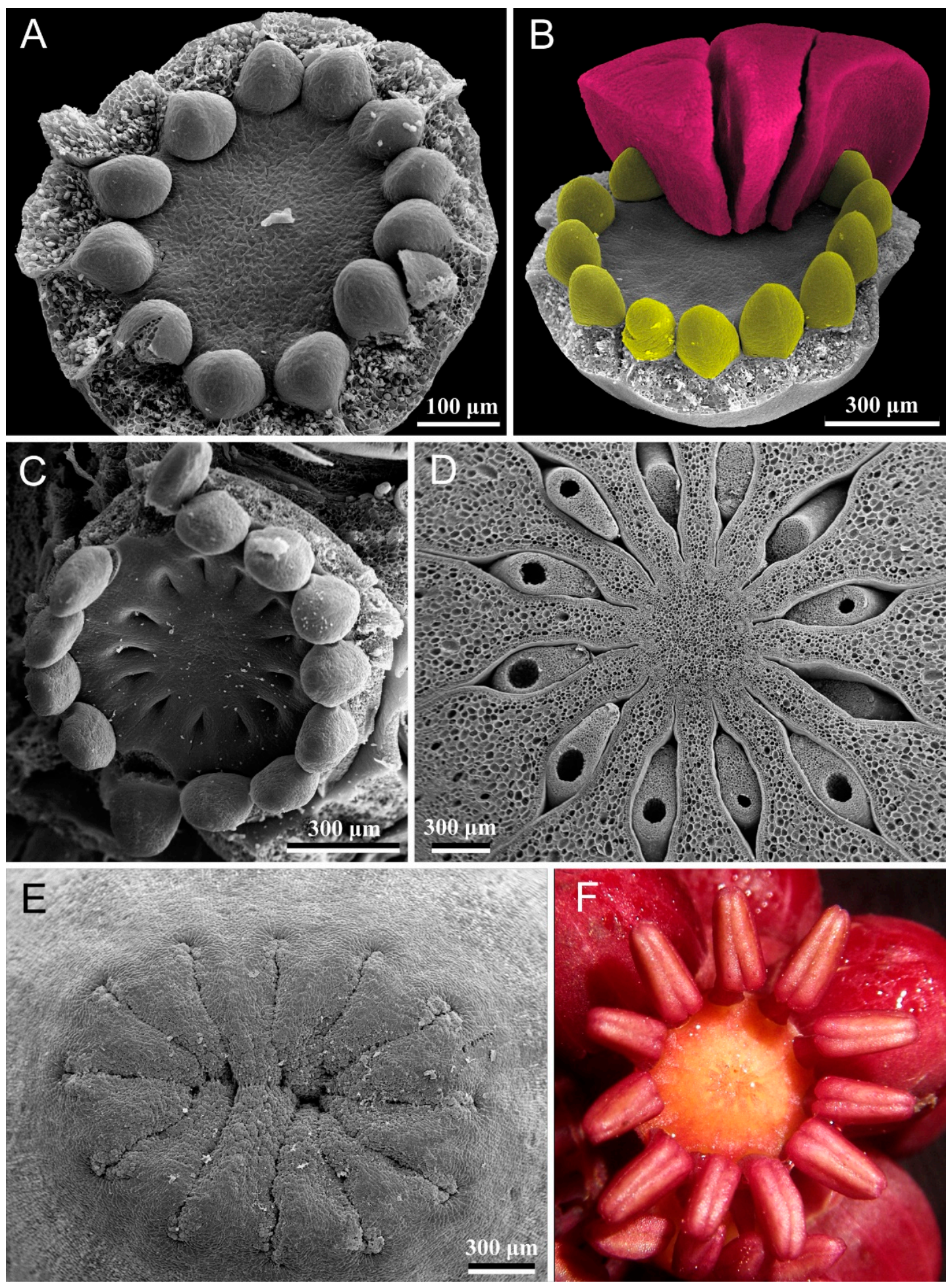

Figure 2. Flowers of Schefflera actinophylla (Araliaceae). (A). Carpel initiation stage, top view; perianth removed (scanning electron microscopy, SEM). (B). Carpel initiation stage, oblique view; perianth removed except for three petals (SEM). (C). Gynoecium development stage, top view; perianth removed (SEM). (D). Cross-section of the mature ovary, synascidiate zone (SEM). (E). Mature gynoecium, top view, showing the arrangement of the postgenital carpel fusion in the symplicate zone (SEM). (F). Anthetic flower with abscised petals, top view. 

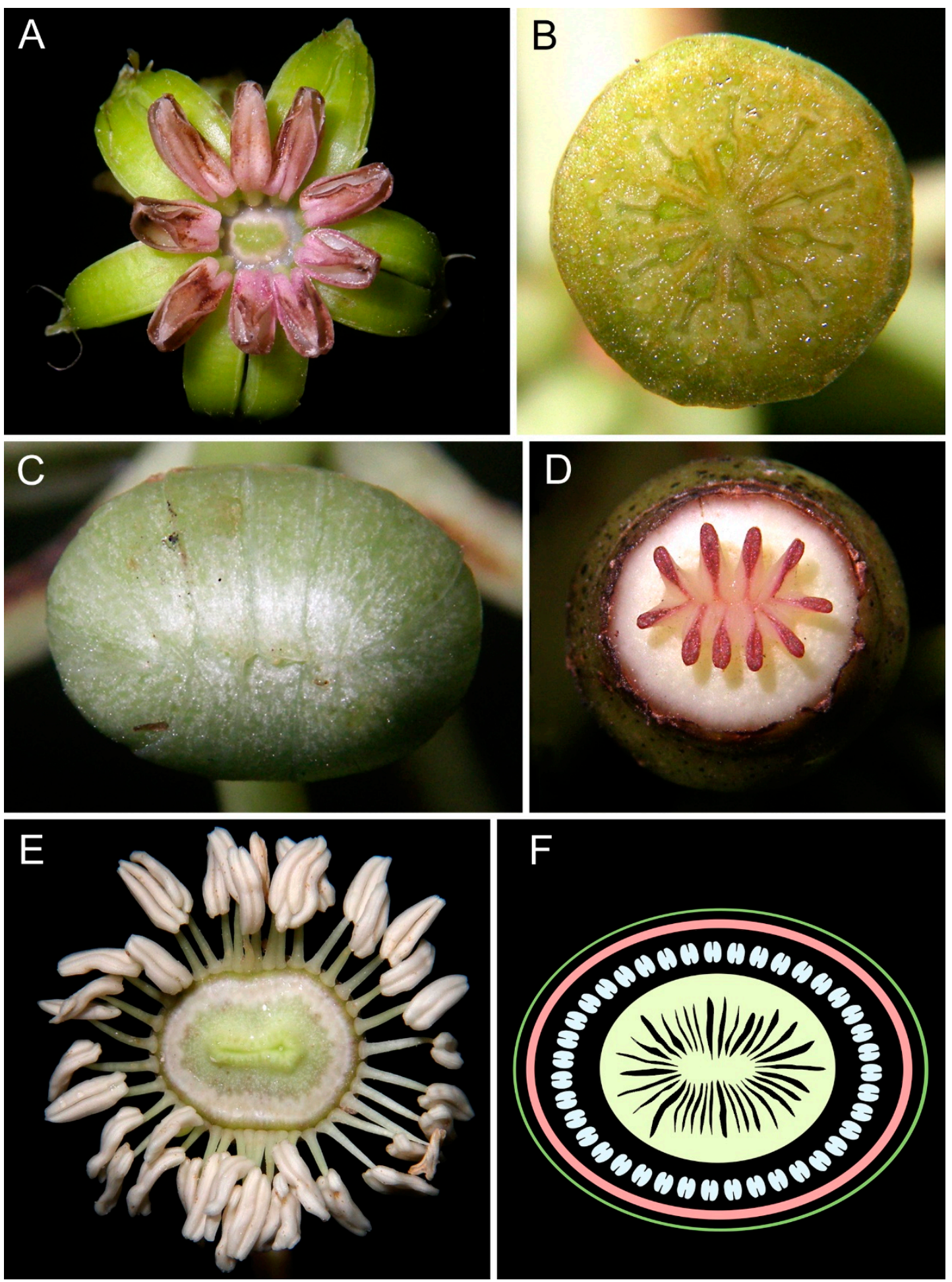

Figure 3. A-D. Flower of Polyscias duplicata (Araliaceae). (A). Anthetic flower, top view. (B). Cross section of mature ovary, synascidiate zone. (C). Mature flower bud, top view; note the arrangement of petal tips. (D). Post-anthetic flower (or flower at the female stage?), top view; petals and stamens abscised. (E). Anthetic flower of Schefflera subintegra (Araliaceae), top view; corolla abscised. (F). Floral diagram of S. subintegra. 

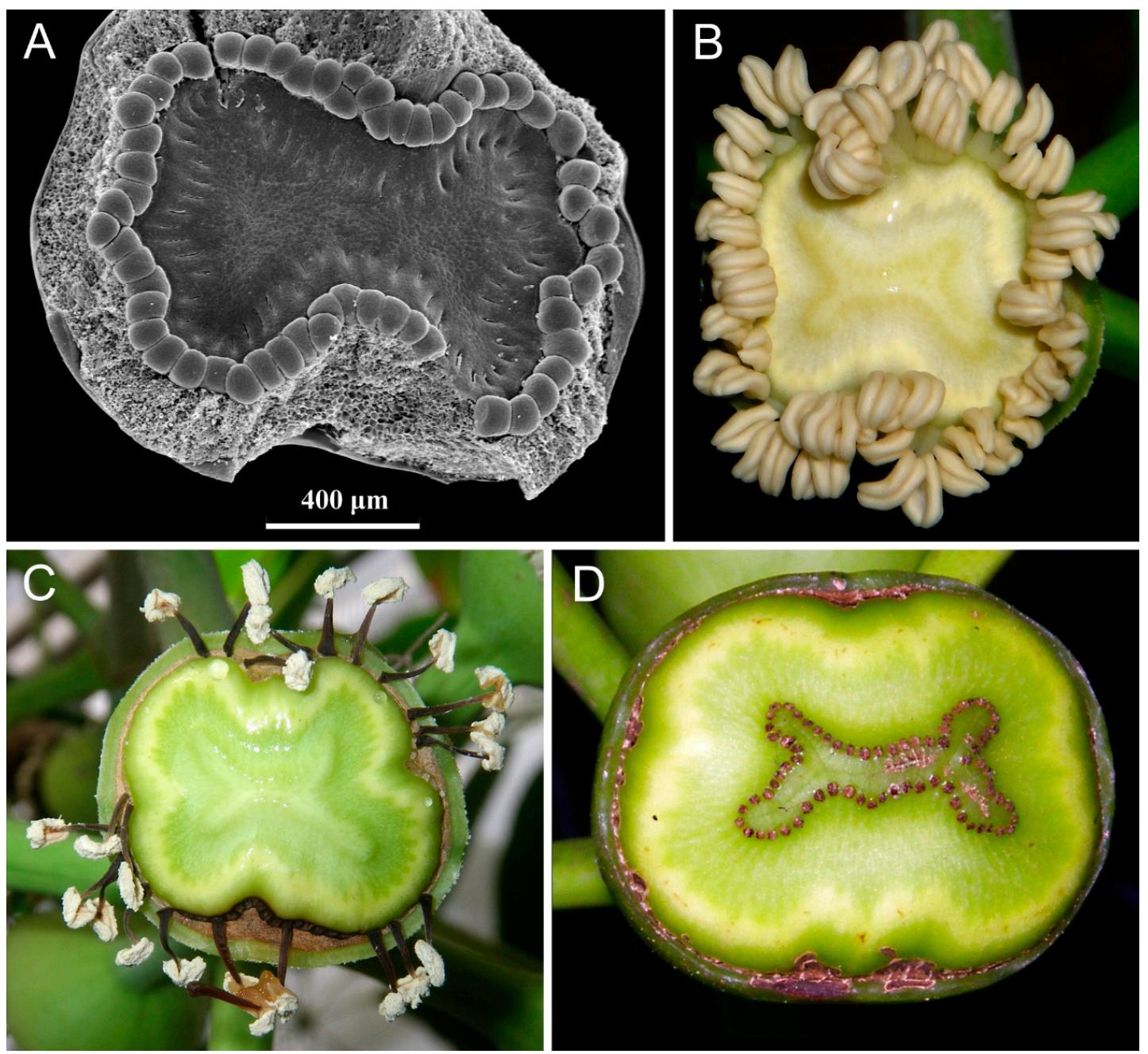

Figure 4. Flower of Tupidanthus calyptratus (Araliaceae). (A). Gynoecium development stage, top view; perianth removed (SEM). B, C. Early (B) and late (C) anthetic flower, top view; corolla abscised. (D). Young fruit, top view.

It is notable that disymmetric flowers of this groundplan can occur due to different developmental pathways. Flowers developed through these pathways can sometimes be recognized even in the definitive state (i.e., in mature flower buds) due to specific morphological features. Examples of such pathways are described below.

(i) In species with slightly polymerous flowers (with up to ca. 15 elements in each whorl), such as Schefflera actinophylla (Figure 2) and S. brevipedicellata $[3,28,60]$, all floral whorls and the entire flower are initially polysymmetric (Figure $2 \mathrm{~A}-\mathrm{C}$ ), and the switch to disymmetry occurs during the development of the symplicate gynoecium zone. As a result, in a preanthetic flower, the disymmetry is mostly pronounced in the gynoecium, where it is manifested in the arrangement of the plicate carpel parts in the symplicate zone in two rows along the central (radial) plane (Figures 2E and 3D); the synascidiate zone remains polysymmetric (Figures $2 \mathrm{D}$ and $3 \mathrm{~B}$ ). In addition, the petal tips tend to be arranged into two alternate rows along the same symmetry plane in a flower bud, forming a zig-zag line if viewed from the top (Figure 3C). Notably, the plane along which the plicate carpel parts and the petal tips are lined up (which represents one of the two flower symmetry planes) occupies an unstable position in relation to the inflorescence axis.

(ii) In Schefflera subintegra [3,31], which possesses moderately polymerous flowers (with 15-43 elements in each whorl), the flower is polysymmetric at the earliest stages of the development of calyx and corolla. By the time the corolla completely covers the floral center, the outline of the entire 
young flower changes into a pronouncedly elliptic one. Consequently, the mature flower displays disymmetry in each whorl, as well as in its receptacle; in particular, it shows a two-rowed arrangement of carpels in both synascidiate and symplicate zones (Figure 3E,F). Morphologically, the carpels here are still arranged in one whorl, as in all other members of Apiales, but the outline of the whorl is pronouncedly elliptic rather than round, so that in the middle part of the gynoecium, the carpels seem to be arranged in two rows facing each other at their ventral sides. By contrast with the previous case, the symmetry planes of flowers in S. subintegra are fixed with respect to the inflorescence axis: the widest side of the flower lies transversally, and thus, the two planes of symmetry are the transverse and median ones.

(iii) The disymmetric flowers of Tupidanthus calyptratus [3,32,61], which is unique among Apiales in having extremely polymerous flowers (with at least 60-172 elements in the stamen and carpel whorls), do not change their shape during development, and thus, they never show radial symmetry (Figure 4A). With respect to the symmetry type, the disymmetric flowers of $T$. calyptratus are equal to those of S. subintegra (case ii) in their mature condition, but they differ from them at the early developmental stages, i.e., by the formation of disymmetric floral primordia. Notably, this species shows a range of floral symmetry types, despite being uniform in general floral morphology (see below). Given the peculiar shape and the high merism of the flowers of T. calyptratus, the boundaries between the types of floral symmetry are imprecise in this species, and the flowers that are treated here as disymmetric often show some deviations towards asymmetry.

\subsection{Monosymmetric Flowers}

This type unites the flowers of Apiales with diverse morphology.

a. Flowers with dimerous gynoecium and pentamerous other whorls (Table 1: M1-M3, A2). Flowers of this groundplan usually possess a polysymmetric calyx, corolla, and androecium, and a disymmetric gynoecium in Apiales (Figure 5A-C). The polysymmetric whorls are characterized by an uneven number of symmetry planes (namely, five). The orientation of the gynoecium in these flowers is fixed with respect to the other whorls, as well as to the inflorescence axis (i.e., the carpels lie in the median plane), so that one carpel is arranged opposite to a petal, while the other one is arranged opposite to a stamen (and to a sepal). Thus, one of the two planes of symmetry of the gynoecium (which is the median one) coincides with a plane of symmetry to the rest of the flower, which results in a median monosymmetry of the entire flower. This floral groundplan can be regarded as being the most common in Apiales: it characterizes the vast majority of Apiaceae and both genera of Myodocarpaceae [30], and represents one of the main types in Araliaceae. 

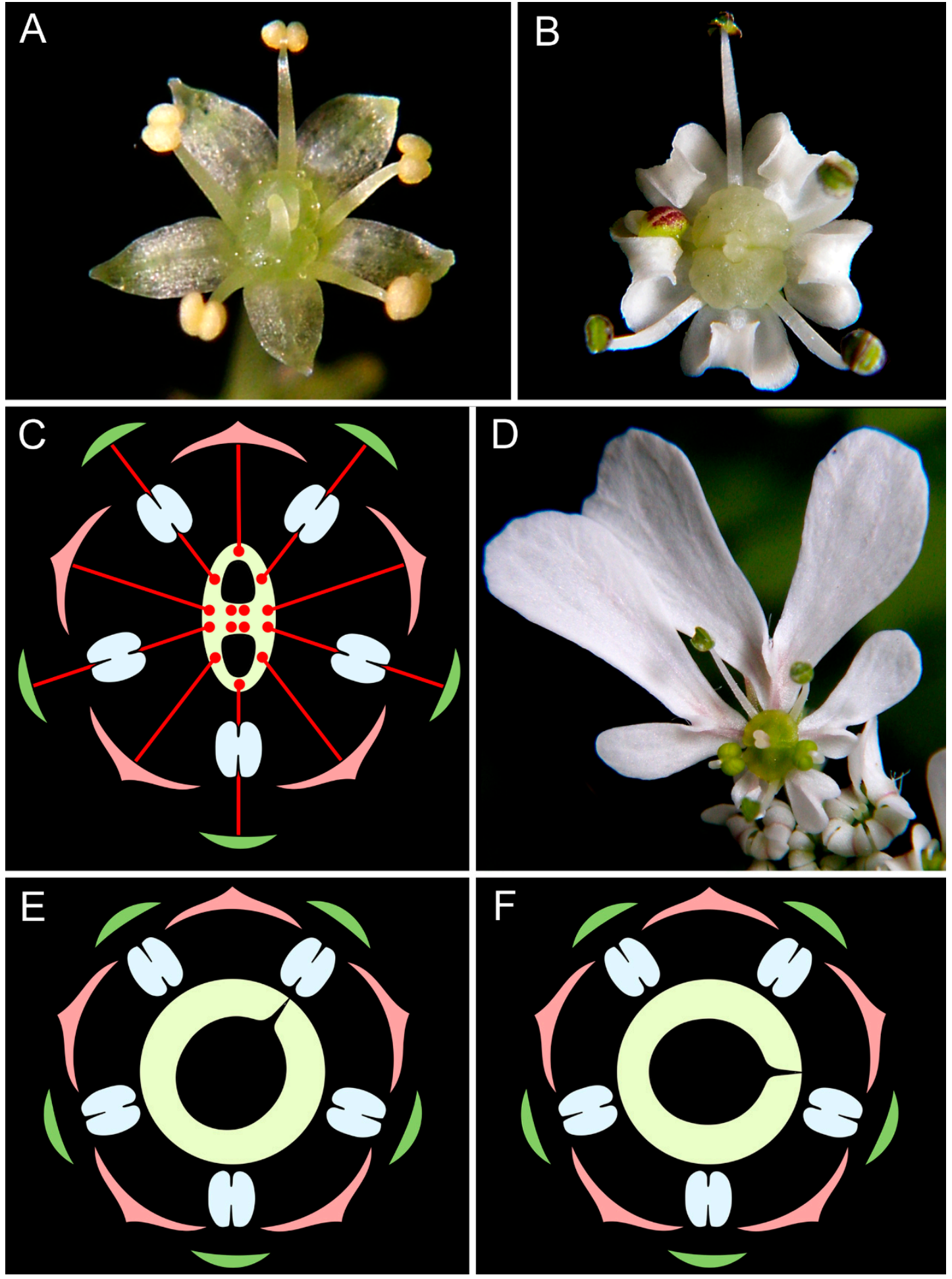

Figure 5. Flowers of Apiales. (A). Hydrocotyle nepalensis (Araliaceae), top view. (B). Thyselium palustre (Apiaceae), top view. (C). Generalized diagram of flowers of Apiaceae and Araliaceae with a dimerous gynoecium and pentamerous other whorls, with superimposed main vascular bundles. (D). Peripheral flower of Tordylium aegyptiacum (Apiaceae), top view. E, F. Floral diagrams of unicarpellate Polyscias spp. (Araliaceae), with the carpel oriented at the radius of stamen (E) and between the radii of the stamen and petal (F).

In this case, the monosymmetry of the entire flower appears to be an effect of the mutual arrangement of the floral whorls, as long as none of the floral structures or whorls possesses this 
symmetry type if treated individually. However, this cumulative monosymmetry is explicitly evident in the structure of the floral vascular system (Figure 5C). Each of the two carpels is innervated by a dorsal vascular bundle; one of the dorsal bundles is united with a petal bundle in the wall of the inferior ovary, while the other dorsal bundle is united with a stamen bundle (and also a sepal bundle, if any). The gynoecium vascular system can thus be regarded as a monosymmetric structure within the flower; see also [62-64].

Some flowers with more complicated morphology also fall within this groundplan. An example of such elaboration is the presence of a monosymmetric corolla (Table 1: M2) in the peripheral flowers of umbels in many representatives of Apiaceae (Figure 5D) [40], and in Trachymene pilosa (Araliaceae) [41]. The corolla monosymmetry in these plants is manifested in the unequal size of the petals, as well as in oblique shape of the two lateral petals. The plane of the symmetry of corolla is median, and therefore, the entire flower is characterized by median monosymmetry, as in the general case described above. The other example is a pseudomonomerous gynoecium (Table 1: M3), known in several genera of Apiaceae (e.g., [65]). The different structure of the two carpels in the gynoecia of these representatives leads to the monosymmetry of the gynoecium, and the entire flower is, again, monosymmetric. Certain species of Hydrocotyle (Araliaceae) and several representatives of Apiaceae that are characterized by dimorphic (though both apparently fertile) fruiting carpels are possibly also relevant here $[66,67]$. For most of them, it is still to be elucidated whether the dimorphism takes place at anthesis (and thus it contributes to the establishment of floral symmetry) or appears during fruit maturation. For Polemanniopsis marlothii and Steganotaenia araliacea (Apiaceae), the prominently different morphology of the anthetic carpels has already been demonstrated [42]. Therefore, the gynoecium is monosymmetric in these species. Finally, a number of species of Trachymene (Araliaceae) are known to possess bicarpellate fruits with a single fertile carpel [41,68]. Some of these species are described as having an "asymmetrical, functionally unilocular ovary" at female anthesis [41] (p. 14), which indicates that their gynoecia can potentially be regarded as monosymmetric, similar to the pseudomonomerous gynoecia of Apiaceae.

b. Flowers with a monomerous gynoecium (Table 1: M4). A gynoecium consisting of a single carpel is a rare feature in Apiales. It is known only in several species of the genus Polyscias (Araliaceae) [45]. In these species, calyx, corolla, and androecium are polysymmetric and normally pentamerous. The single carpel possesses a plicate zone, and therefore the gynoecium is monosymmetric. The symmetry of the entire flower depends on the orientation of the carpel with respect to the other whorls. In flowers with the ventral slit of the carpel occupying the radius of a petal or a stamen (e.g., Figures 3D, 4C-E, 10E in [45]), the symmetry plane of the gynoecium coincides with one of the symmetry planes of the rest of the flower, which results in the monosymmetry of the entire flower (Figure 5E). However, in the cases of oblique carpel orientation, the flower appears to be asymmetric (see $4 \mathrm{~b}$ ), because the symmetry planes of the gynoecium and the other whorls do not coincide. Thus, not all of the flowers with monomerous gynoecium are monosymmetric in Apiales.

It should be noted that the determination of the carpel orientation with respect to the other whorls is somewhat conventional in such cases. If the outer whorls are pentamerous, then there are 10 radii of the outer elements, and therefore, one should distinguish the modes carpel orientation differing by $18^{\circ}$ to find out whether it is opposite to a petal or a stamen, or whether it is oblique. However, in the cases of Polyscias described here, the flowers appeared to be easily divided into these types, based on the images of young flowers showing a broad ventral slit, with its outer border at close proximity to the stamens.

c. Flowers with trimerous gynoecium (Table 1: M5). In most representatives of Apiales with the gynoecium of three carpels, the gynoecium orientation is unstable (but see the exceptions below, under $3 \mathrm{~d}$ ), and special investigations are needed to prove the occurrence of flowers with one of the carpels arranged in a radius of a petal or a stamen, which would lead to a monosymmetry of the entire flower. This "properly" arranged carpel can be represented by any of them if they all are fertile, and should be the fertile one if the gynoecium is pseudomonomerous. In theory, this situation is similar to that of 
the monomerous gynoecium (see 3b), but, in contrast to the cases of the unicarpellate taxa, here, very few records of the "proper" (monosymmetric) gynoecium orientation are known. One such example is Cheirodendron trigynum (Araliaceae). Even in this species, the oblique gynoecium orientation is a prevailing condition; thus, in the tricarpellate species of Apiales with unstable gynoecium orientation, most of the flowers (and frequently all of them) are asymmetric; this condition is described below (see $4 a)$.

d. Flowers with a pseudomonomerous trimerous gynoecium that occupies a stable orientation with respect to the other floral whorls (Table 1: M6, A3). Among Apiales, flowers of this type are known in Melanophylla (Torricelliaceae) [6]. This genus is characterized by a pentamerous calyx, corolla and androecium; the fertile carpel is arranged in the radius of a petal. Similar to the case of unicarpellate flowers (3b), here, the only symmetry plane of the monosymmetric gynoecium coincides with one of the symmetry planes of the polysymmetric remainder of the flower, which results in a monosymmetry of the entire flower. Notably, the plane of floral symmetry in Melanophylla is constantly transversal, which is an effect of a transversal position of the fertile carpel, and more remarkably, a transversal position of one of the sepals. The latter fact is remarkable, because it means that none of the sepals or petals is median. This pattern of flower orientation is very rare in angiosperms, as most of them possess either a sepal or a petal in a median adaxial position [29,69]; within the typical orientation, in flowers with uneven perianth merism, transversal monosymmetry is impossible.

e. Highly polymerous flowers of Tupidanthus calyptratus (Araliaceae) (Table 1: M7). These are flowers of the same groundplan, as described for this species in $2 b$, differing in the monosymmetric shape of the receptacle and the floral whorls (Figure $4 \mathrm{D}$ ). The plane of symmetry is constantly median [32].

\subsection{Asymmetric Flowers}

This type of floral symmetry is associated mostly with an unstable orientation of the gynoecium in Apiales, because the asymmetry of an individual floral whorl is extremely rare in this order. For this reason, this type is found in taxa that also possess flowers with other symmetry types.

a. Flowers with trimerous (and tetramerous) gynoecium (Table 1: A5, A6). Species with a trimerous gynoecium (sometimes also possessing flowers with gynoecium of other merism) are scattered in a wide range of lineages in Apiales, including a number of genera of Araliaceae and Pittosporaceae, as well as almost all representatives of the small families Griseliniaceae, Pennantiaceae, and Torricelliaceae. A trimerous gynoecium itself is characterized by polysymmetry in Apiales, or by monosymmetry in case of pseudomonomery; the other whorls are polysymmetric, with merism higher than three (most often pentamerous). The orientation of the gynoecium with respect to the other whorls is mostly unstable and oblique in these taxa (e.g., [45]; Karpunina et al., in prep.), which makes the entire flower asymmetric. The rare cases of non-oblique orientation in some of the flowers of a given species are treated as monosymmetric flowers (see 3c). The only prominent exception from the unstable pattern of gynoecium orientation is the pseudomonomerous gynoecium of Melanophylla, which is transversally monosymmetric, as well as its entire flower (see 3d).

A tetramerous gynoecium is quite rare in Apiales, and is found in species with variable number of carpels within a range of its variation. This condition is usually combined with pentamerous other floral whorls (e.g., some species of Pittosporum, Pittosporaceae; [70]) resulting in an asymmetry of the entire flower, similar to the case of a trimerous gynoecium. However, if all of the whorls are tetramerous, the flower is polysymmetric (see 1a).

b. Flowers with monomerous gynoecium (Table 1: A4). This type is represented by flowers of the same groundplan, as described in $3 \mathrm{~b}$, differing by an oblique carpel orientation (Figure 5F). It occurs within the same range of taxa, i.e., Polyscias spp. (Araliaceae) [45].

c. Highly polymerous flowers of Tupidanthus calyptratus (Araliaceae) (Table 1: A7; Figure 4B,C). Asymmetric flowers occur within the variation of the shape of the receptacle and the floral whorls of this species, as described in $2 b$ and $3 e$ [32]. 


\subsection{Minor Deviations from Polysymmetry in Particular Whorls of Flowers of Apiales}

Apart from the "robust" morphological floral features that are employed in the classification of floral symmetry in Apiales as presented above, one can find an almost infinite number of characters that to some extent disturb the polysymmetry of a particular part of a flower. We find it impractical to take them into account for the determination of the symmetry type of an entire flower. However, these deviated traits are also worthy of consideration, because they regularly occur in certain lineages within Apiales as characteristic features of their floral groundplans.

1. Aestivation of the calyx and corolla (and rarely androecium) (Table 1: A1-A3, A6). A perianth whorl that is otherwise polysymmetric appears in some cases to be asymmetric with respect to mutual overlapping of its elements in the flower bud. Among the most common types of aestivation [29] found in Apiales, there are various patterns of imbricate aestivation (probably excluding the decussate pattern, which is characteristic of whorls with even merism, and which thus should be rare in Apiales, if any). One of the most striking examples here is that of Melanophylla, which possesses prominently contorted petals and stamens [6,71]. The contort pattern is of special interest, because a whorl with this pattern lacks any symmetry planes (and is therefore treated as being asymmetric here), but it still possesses a rotational form of symmetry. The other examples of Apiales with imbricate aestivation of the corolla are found in the families Araliaceae (a few genera), Myodocarpaceae (both genera, i.e., Delarbrea and Myodocarpus), Torricelliaceae (Aralidium) [30,38,39,46-48,72], and in some Apiaceae [49], including Stilbocarpa [47,73]. Besides, the corolla is imbricate in the entire family Pittosporaceae, and moreover, this type of aestivation is found in the calyx of many representatives of this family $[4,50,51,53-56]$.

2. Postgenital fusion of the petals. In certain Araliaceae with moderately polymerous flowers, the petals (or only some of them) remain united in groups of two or three after corolla opening. Depending on the pattern of petal fusion in a particular flower, this may lead to the asymmetry of the anthetic corolla. The examples here are Schefflera actinophylla [3,28,60] and Trevesia palmata [74].

3. Unequal rates of sepal growth. In some Apiales, the sepals are prominently unequal in size during early calyx development $[3,6,27,33,45,71,75,76]$. In such cases, the young calyx is asymmetric, though it is polysymmetric, or nearly so, at maturity.

4. Placentation. In Apiales (except for Pittosporaceae), each fertile carpel uniformly bears a single fertile ovule, which is often accompanied by a single sterile ovule $[34,77,78]$. Each of the ovule(s) is attached on one side of the proximal part of the ventral slit of the carpel. Thus, the carpels in Apiales are asymmetric with respect to the attachment of the fertile ovule, which lies away from the symmetry plane of the otherwise monosymmetric carpel.

5. Deviation of styles. In some Apiales (e.g., Hydrocotyle from Araliaceae, Figure 5A), the styles of a dimerous gynoecium are consistently bent to the opposite sides, away from the symmetry plane of the carpel (and the gynoecium). This feature can be viewed as a manifestation of carpel asymmetry.

\section{Discussion}

\subsection{Types of Floral Symmetry in Apiales: Applications of Various Approaches}

The most widely employed approach divides the flowers of angiosperms into actinomorphic and zygomorphic ones. Typical plants with zygomorphic flowers are many representatives of Fabaceae, Lamiales, Asterales, Commelinales, Zingiberales, Orchidaceae [8-11,15,24,79]; their floral symmetry structurally and ecologically has little in common with that of the monosymmetric flowers of representatives of the order Apiales studied here. Moreover, the flowers that are common in the family Apiaceae (i.e., the pentamerous ones with a dimerous gynoecium), as well as the similar flowers of some Araliaceae were described as being actinomorphic (e.g., [78]), though they are clearly monosymmetric from a structural viewpoint (see above). Only some authors [12] described the typical flowers of Apiaceae (i.e., with both carpels being fertile) as being zygomorphic ones, though there is a possibility that they considered, first of all, peripheral flowers with unequally enlarged petals, as listed under case 3a in our study. Reyes et al. [24] coded Anethum graveolens and Angelica 
sylvestris (lacking enlarged petals in peripheral flowers) as being characterized by actinomorphic flowers, and Coriandrum sativum and Daucus carota (with enlarged petals in peripheral flowers) as being characterized by zygomorphic ones. Besides the fact that the floral monosymmetry of the former species is not taken in consideration within this approach, the striking inconsistency here is that all of the flowers of the latter species are coded as being zygomorphic, though their central flowers are in fact of the same shape as the flowers of the former species. Such a simplification can apparently lead to inadequate results in evolutionary analyses, such as an ancestral state reconstruction.

Endress [11] noted that in Apiaceae, the impact of the pentamerous outer whorls on the dimerous gynoecium may cause a monosymmetry of the latter. This monosymmetry of the gynoecium is present in floral buds, and it may become more pronounced or disappear (being replaced by disymmetry) during later flowering and fruit development. It should also be noted that the symmetry of the flower is tightly related to its en face orientation (with respect to the surface of the earth): typical zygomorphic flowers are oriented horizontally, which is usually a consequence of the precise position of a pollinator in a flower, and is manifested in the arrangement of the trajectory of pollinator movement within the flower parallel to the ground [11,21,80,81]; in contrast, typical actinomorphic flowers are vertically oriented. Exceptions from this pattern are found in some taxa with zygomorphic peripheral flowers of the pseudanthia, which were hypothesized to act as a landing platform for flying pollinators [24]; a comparison between the concepts of medial zygomorphy and dorsoventral zygomorphy that are relevant here was also presented by Neal et al. [7] and Giurfa et al. [12]. The flowers of Apiaceae and some other angiosperm families, despite possessing monosymmetric structure (in the strict sense), are oriented similarly to actinomorphic flowers, i.e., vertically. The enlarged petals of the peripheral flowers of some Apiaceae can hardly be regarded as landing places; more likely, they play a role in the visual attraction of the pollinators.

Endress [11] distinguishes more elaborate and less elaborate forms of floral monosymmetry and asymmetry. In the first case, the deviation from polysymmetry is determined by a high level of organ synorganization, accompanied by a significant difference between the elements within a floral whorl. In the second case, minor differences occur in the shape of certain organs, or the general simplicity of the flower (including cases of loss of some of the organs). Examples with imbricate aestivation (including contort and quincuncial ones) are also treated by Endress [11] under less elaborate asymmetry; here, we prefer not to follow his view, and we have excluded aestivation from the criteria of floral symmetry. We believe it to be more constructive to treat this characteristic separately, as too many taxa would otherwise have to be considered as having asymmetric flowers. Although some Araliaceae with polymerous non-polysymmetric flowers are known to possess synorganization of floral elements (particularly within the corolla, with the formation of a calyptra or a calyptra-like structure [31]), their flowers should most likely be assigned to a less elaborate form, as the di-, mono-, and asymmetry forms found here have no biological significance, and they exclusively represent the effects of certain morphogenetic patterns.

As is evident from the results presented above, floral symmetry in the order Apiales is tightly correlated with the gynoecium merism. In representatives with a carpel number that is lower than the petal number in a flower (i.e., with mono-, di-, and trimerous gynoecium), the application of different criteria leads to the revelation of polysymmetry /actinomorphy or monosymmetry/zygomorphy [7]. Excluding such plants from consideration, one can conclude that isomerous and nearly isomerous flowers with low merism (i.e., pentamerous ones and ones that are similar to them) are characterized, at least in most cases, by a polysymmetry. Deviations from polysymmetry appear when it is "necessary" to arrange a large number of carpels in one whorl.

\subsection{The Impact of Gynoecium Orientation on Floral Symmetry in Apiales}

The floral symmetry types that are distinguished in Apiales are mostly contingent on the merism and the outline of the gynoecium, and especially on the stability or the lability of its orientation, in relation to the other whorls. The gynoecium of polysymmetric flowers found in this order are either 
nearly isomerous to perianth whorls, with the carpels arranged in the radii of the petals (or rarely sepals), or polymerous, with an indefinite number of symmetry planes. All disymmetric flowers in this group also have a stable orientation of gynoecium in relation to the petals, and/or to inflorescence axes. Indeed, the variable orientation of this whorl is found only within mono- and asymmetric flowers. Moreover, the flowers of these two symmetry types can co-occur in the same inflorescences, due to variations in gynoecium orientation.

Generally, the stability of the gynoecium orientation is consistent with the assumption of the existence of two directions of spatial pattern formation (prepatterning) in the floral meristem, namely, acropetal patterning for the perianth, and basipetal patterning for carpels and stamens. According to this model, the sepals are the first to be patterned, and therefore, they affect the patterning of carpels; in turn, the positions of the stamens and the petals are correspondingly governed by carpels and sepals [2,82-84]. In Apiales, indirect evidence for the basipetal patterning of the gynoecium and androecium has even been reported for Tupidanthus, with its extremely numerous stamens and carpels [32]. At the same time, the occurrence of flowers with variable gynoecium orientations, as well as the presence of multiple carpels in otherwise pentamerous flowers can hardly be explained by this model [2]. One can speculate that the presence of basipetal patterning is correlated with floral polysymmetry and disymmetry in Apiales.

\subsection{The Impact of Merism and the Outline of the Polymerous Gynoecium on Floral Symmetry in Apiales}

In Apiales, a gynoecium with more than five carpels occurs only in the family Araliaceae, and therefore, only examples from Araliaceae are discussed below. Our results show that the variation of floral symmetry in Araliaceae largely represents a consequence of certain developmental constraints. Several kinds of such constraints are found, which are reflected in differences in the shape and symmetry of flowers at particular developmental stages and/or in anthetic condition.

(1) Flowers with slightly polymerous gynoecium, consisting of up to ca. 15 carpels, are polysymmetric at the beginning of their development. Their disymmetry is manifested since the late stages, with regard to the arrangement of the plicate carpel parts within the symplicate zone. The arrangement of the plicate carpel parts in two rows is regarded here as a method of establishing a contact between all of the carpels, which cannot be reached in the central axis of the flower, in the case of the large number of carpels. The necessity for such a contact follows from the presence of a compitum in Araliaceae: indeed, the intragynoecial compitum is known to be one of the key advantages of the syncarpous gynoecium $[85,86]$, and it is obligatory in all Apiales with more than one carpel in a flower, including the cases of a single fertile carpel [6,72]. As a result, a disymmetric arrangement of carpels in two rows commonly arises in the polymerous gynoecia.

A similar explanation can be applied for the disymmetric arrangement of petals in the buds of Schefflera actinophylla, belonging to this morphological group of species (with slightly polymerous gynoecium), as well as in some other Araliaceae with polymerous corollas: a close contact between the petals is required, because they provide bud protection in Araliaceae. The coincidence of the symmetry planes of the symplicate gynoecium zone and the corolla in S. actinophylla suggests the presence of a common regulatory mechanism; possibly, the petals are arranged according to the slightly elliptic shape of the distal part of the gynoecium, caused by the specific arrangement of the plicate carpel parts. This is probably facilitated by the (semi)inferior ovary position.

It should be noted that deviations of this kind also occur in oligomerous corollas and gynoecia (i.e., those of up to six petals and carpels) of Apiales. In a number of representatives from various lineages, an imprecise arrangement of valvate petals in the flower bud was recorded, manifested in the absence of a simultaneous contact between all the petals, e.g., by one of them being smaller and not reaching the floral center, and contacting only with two neighboring petals $[3,28,45,61]$. Similarly, in several species of Schefflera (Araliaceae) with a 5-6-merous gynoecium, an asymmetric contact between the plicate carpel parts was found $[3,28,61]$. It remains unclear whether this is indeed an effect of morphogenetic difficulty for precise contact between organs, or just a case of a minor variation of petal 
and carpel shape, which is possibly correlated with slightly asynchronous organ initiation and/or early development. We assume the latter option to be more plausible, and thus we treat such corollas as being polysymmetric.

(2) Among flowers with moderately polymerous gynoecium (with about 15-50 carpels), those of Schefflera subintegra are studied in detail. In this species, the shape of the whole flower changes from polysymmetry to disymmetry early in development; i.e., when the corolla tube completely covers the undifferentiated floral center. The flower is thus already prominently elliptic in outline by the time of the initiation of the androecium and gynoecium. We argue here that the most important factor leading to the disymmetry of the entire flower is the occurrence of a constraint (whose nature merits further studies) that maintains the arrangement of a large number of elements in a single whorl. If the primordia of the elements (stamens or carpels) of the same number and size are arranged polysymmetrically along a circular whorl, the entire flower would inevitably be disproportionally large, with a huge unused central area. This is especially crucial for the innermost whorl of the flower, i.e., the gynoecium (see also [87]).

The fixed orientation of the flower with respect to the inflorescence axis (with transversal broader side) can be provisionally explained by the interaction between the developing flower and its subtending bract by the means of mutual pressure [88]. At the establishment of disymmetry, the flower probably enlarges and broadens according to the available space, which is the space with the lowest pressure from both the bract and the axis.

(3) Highly polymerous flowers of Tupidanthus calyptratus show the most complex shape in Araliaceae, which is prominent from the stage of the floral primordium when no floral elements are differentiated. While the receptacle of Schefflera subintegra can be described as being transversally compressed, that of $T$. calyptratus is folded several times (often butterfly-like). The carpels of the single whorl are aligned on both sides of a branching line. This species thus shows a next-step complication that is aimed at packing an extremely high number of floral elements. According to the particular patterns of receptacle folding, the flowers of T. calyptratus are di-, mono-, and asymmetric.

Following the ideas of Endress [8,11], the flowers of Schefflera actinophylla, S. subintegra, and other species of Araliaceae with similar groundplans (at least for those for which comprehensive data on floral development is available) can be described as being disymmetric with early polysymmetry. The loss of polysymmetry during morphogenesis is usually related to the unequal growth of certain floral parts $[8,10,89]$. However, in species of Araliaceae studied here, the elements of each floral whorl are uniform (equally developed), and the symmetry change appears exclusively as a result of the corresponding arrangement of the elements in some or all of the whorls, sometimes accompanied by a shift in receptacle shape. Besides, an opposite example can be found in Apiales: many species are characterized by a sequential sepal initiation, resulting in drastic size differences between the sepals at the early stages of calyx development $[3,6,27,33,45,71,75,76]$. At the later stages, the sepals acquire an equal size, and the mature calyx is polysymmetric. Such flowers, if not asymmetric in preanthetic condition due to any other reasons, can be treated as being poly-/monosymmetric with early asymmetry $[8,11]$.

As is evident from the results presented here, the deviations from floral polysymmetry in Araliaceae with increased floral merism are nothing but a "necessary measure" for the disposition of a large number of elements (first of all, carpels) within a floral whorl, including the establishment of contacts between the carpels to form a compitum. The cases of such deviations across angiosperms with multicarpellate gynoecia were reviewed by Endress [87]. They follow from the general regularities of spatial organization of the angiosperm flower, and do not represent adaptations to any ecological factors, such as patterns of interaction with pollinators, seed production, or dispersal. This is the main difference between the representatives of Araliaceae with polymerous non-polysymmetric flowers, and taxa of the asterid orders Lamiales, Asterales, etc., characterized by zygomorphy that is directly associated with adaptations to entomophily $[10,11,90]$. Notably, in the latter groups, the zygomorphic flowers are predominantly pentamerous $[8,20,79]$. While in most euasterids (probably excluding 
Oleaceae), the meristic changes in flowers (usually towards the reduction of the number of elements) occur under the influence of zygomorphy [91], in Araliaceae, vice versa, an increase of floral merism leads to a shift from polysymmetry to a disymmetry. In other words, the shifts in floral symmetry are a consequence of meristic changes in Araliaceae and their reason in most other euasterids. A remarkable exception from this pattern is found in euasterid taxa with pseudomonomerous gynoecia [92] and polysymmetric other floral whorls: similarly to the cases of Araliaceae, their non-polysymmetry is a consequence of certain morphological traits, and is not related directly to the pollination process.

Endress [11] stresses that floral monosymmetry has crucially different structural nature in different taxa: it affects all of the types of floral elements or only a part of them; it is associated with differential organ shape, fusion, or number; the plane of symmetry occupies various position (median, transverse, oblique) with respect to the axis of the previous order. Monosymmetry is also a characteristic of all flowers with monomerous whorls (most likely except for cases where the lone element occupies a central position and itself is not monosymmetric, as well as the cases of its oblique orientation); it is classified by Endress [11] as being monosymmetry by simplicity. Endress [11] (p. 351) also distinguishes organizational monosymmetry, resulting from the corresponding "initial disposition of young organs", and the architectural monosymmetry manifested in the "shape of the anthetic flower". The latter type is usually shallow, while the former one is more prominent. The "typical" zygomorphic flowers often combine both of these types. It is likely that these concepts are related to the ideas of changing vs not changing expression of floral symmetry (during flower development), resulting in a transient vs constant monosymmetry and asymmetry, proposed by the same author $[8,11]$. The latter ideas not only deal with element arrangement, but also with the shape of the receptacle and the elements. Apparently, an attempt to apply this complicated classification of non-polysymmetric flowers to the family Araliaceae will lead to a revelation of a combination of several modi in a number of its representatives, especially in those with polymerous gynoecia.

\subsection{Orientation of Disymmetric and Monosymmetric Flowers Relative to the Inflorescence Axis in Apiales}

Typical zygomorphic (monosymmetric) flowers are characterized by a precise orientation of the symmetry plane with respect to the inflorescence axis $[7,11,15,93]$, which is structurally conditioned by the presence of floral elements of different morphology (or with uneven placement of the elements) within at least one whorl, and their stable arrangement $[15,20]$, and functionally related to a corresponding stable position of the animal pollinator during the visits $[10,11,90]$. As follows from our study, some representatives of the family Araliaceae (apart from those with monosymmetry by simplicity: see below) possess a variable orientation of disymmetric and monosymmetric flowers with respect to the inflorescence axis (e.g., Schefflera actinophylla and S. brevipedicellata with slightly polymerous gynoecium). We consider this variation as an additional argument in favor of the idea that a deviation from polysymmetry in these species occurs exclusively due to certain spatial constraints, namely, the necessity of contact of a large number of elements of the same whorl, and is not triggered by any adaptations to interactions with pollinators.

On the other hand, the disymmetric flowers of Schefflera subintegra studied here possess a constant orientation relative to the inflorescence axis, i.e., with the broader side in the transverse position. Most likely, the disymmetric floral shape of this species is partly conditioned (in the mechanical and/or regulatory context) by the structures surrounding the flower. The same is true for the disymmetric and monosymmetric flowers of Tupidanthus calyptratus; in the monosymmetric flowers of this species, its symmetry plane is uniformly median.

The species of Araliaceae possessing floral monosymmetry as an effect of monomerous gynoecium studied to date (monosymmetry by simplicity, following Endress [11]), i.e., the unicarpellate Polyscias species, are characterized by the variable orientation of the single carpel relative to the inflorescence axis [45]. Clearly, in this case, similar to the cases described above, the orientation of the plane of floral symmetry bears no functional significance. 
In transversally monosymmetric flowers of Melanophylla, the fixed orientation of the symmetry plane is most likely caused by the tight interactions between the neighboring floral whorls (starting from those between the bracteoles and the calyx) during flower development, or at the stage of prepatterning of floral organs [6,71]. Finally, the flowers of Apiales with a dimerous gynoecium and pentamerous other whorls are always (or almost so) monosymmetric, with a uniformly median plane of symmetry. Here, the stability of the orientation is apparently a result of the general rules of the arrangement of elements in the angiosperm flowers: indeed, in most eudicots with a dimerous gynoecium, the carpel position is fixed relative to both the outer whorls and the inflorescence axis [29].

\subsection{Implications for the Evolution of Floral Symmetry in Asterids}

It is well-known that within both eudicots and monocots, zygomorphic flowers generally characterize more "advanced" groups, i.e., phylogenetically more deeply nested ones, which possess a stable floral structure that is manifested in a constant number of elements and their arrangement $[14,15,20]$. In asterids that show diverse types of floral symmetry, the ancestral flower groundplan is probably the actinomorphic one with a pentamerous perianth and a moderate number of stamens [20]. An analysis of floral symmetry in asterids with the consideration of the number of petals, stamens, and spurs in a flower has revealed that zygomorphic flowers nearly always possess a fixed number of elements in each whorl, and that this number is most often five [20]. The presence of spurs constantly coincides with zygomorphy in this clade. Zygomorphy is particularly correlated with oligandry, and a high stamen number is supposed to hinder heterogeneous development of organs. It was argued that zygomorphy is possible only within a strictly fixed structure of the whole flower [20], and associated with a high level of specialization [15].

According to Jabbour et al. [20], Tupidanthus is one of the two genera of asterids whose flowers are characterized by both zygomorphy and polyandry. Meanwhile, the zygomorphy of the perianth has evolved in asterids more than 30 times [24] (most likely even more times, because this work does not take into account the case of Tupidanthus). This character is believed to be controlled by a complex network of transcription factors and target genes, and also modulated and constrained by interactions with other architectural floral traits [20]. In most studied cases of apparently independent origin of zygomorphy in angiosperms, the CYCLOIDEA-like genes are responsible for development of this character [14,20] (but see [94]). Expression of these genes in dorsal regions of floral meristem is responsible for pre-patterning of its monosymmetry at early developmental stages, which is further resulted in the formation of unequal organs of calyx, corolla and androecium $[95,96]$. This genetic mechanism can be potentially involved in the regulation of the formation of the peripheral zygomorphic flowers with pronounced differences in petal sizes occurring in the umbels of some Apiaceae. However, it is likely that the genetic and developmental nature of the deviations from floral polysymmetry in other Apiales, including Tupidanthus, differs radically from that of most asterids; rather, we predict that they are conditioned exclusively by the patterns of structure and development of the flower, and not governed by the CYCLOIDEA-like genes. Moreover, the deviations from polysymmetry (including monosymmetry, which one can synonymize with zygomorphy) in Araliaceae seem to be associated neither with the presence of elements of different structure within one whorl, nor with their uneven arrangement; they occur due to a peculiar structure of the receptacle (and correspondingly, the peculiar shape of the outline of each whorl) and/or the mode of interaction between the elements of a whorl, in the case of their contact or postgenital fusion. Particularly, the non-actinomorphy of flowers of Tupidanthus may be hypothetically considered to be an aftereffect of the fasciation of the floral meristem caused by (as-yet undiscovered) mutation(s) in gene(s) of the CLAVATA family [32].

Besides, there are species of Araliaceae with flowers that are non-polysymmetric by simplicity, such as those with unicarpellate or bicarpellate gynoecium. Thus, the non-polysymmetric flowers of various kinds in Araliaceae (except possibly for those of Trachymene pilosa with enlarged outer petals) do not differ from the polysymmetric (actinomorphic) flowers of the representatives of this family 
in their mode of interaction with a pollinator; that is, the pollinator apparently does not recognize them as being bilateral (i.e., disymmetric or monosymmetric) and, it takes an arbitrary position while visiting them. The rest of Apiales generally fits well into this picture. The most prominent exceptions are flowers with monosymmetric corollas in some Apiaceae; these flowers possess petals of different structure, play special role in interactions with pollinators, and thus can be unequivocally regarded as zygomorphic flowers. Another case of a whorl with elements of different morphology is the gynoecium of dimorphic carpels (including the pseudomonomerous gynoecium) found in several families of Apiales; these flowers are biologically more similar to actinomorphic than to the zygomorphic ones.

\section{Conclusions and Prospects}

The specificity of the diversity of floral symmetry in Apiales can be summarized as the following.

The taxa of this order are diverse not only in the floral symmetry itself, but also in the patterns of variability of this feature between individual flowers and in the morphogenesis of a given flower. Particularly, in some species, the symmetry of all their flowers is rather uniform, while in the others it varies within considerable limits. Also, in some species, the floral symmetry is constant from the early stages of floral development up to anthesis, while in the others, a shift of symmetry takes place at an earlier or later stage, sometimes resulting in different symmetry for different parts of a preanthetic flower.

The basic (i.e., the most common) type of floral symmetry in Apiales is polysymmetry. The polysymmetry of individual floral whorls, possibly except for the gynoecium, is most likely an ancestral condition for the whole order [20]. Several evolutionary reasons for deviations from polysymmetry can be outlined; sometimes more than one of them are found in a particular flower. (1) Evolution of a pollination syndrome. Despite being generally common in zoophylous angiosperms, this case is extremely rare in Apiales, and it is represented only by the peripheral flowers of some Apiaceae and of Trachymene pilosa (Araliaceae). All of the other cases are nothing but reflections of the intrinsic features of the structure and development of a flower. (2) A wide range of flowers fall within non-polysymmetric types due to purely geometrical reasons, including monosymmetry and asymmetry by simplicity. These are (2a) flowers with a monomerous whorl, which are represented by unicarpellate flowers in Apiales; ( $2 b$ ) flowers with superimposed whorls of different symmetry, resulting in a symmetry of the entire flower that is distinct from that of the individual whorls; (2c) flowers with a polymorphism of elements in a whorl, which are represented by flowers with dimorphic carpels (including those with pseudomonomerous gynoecium) in Apiales. (3) Finally, there are flowers whose non-polysymmetry is a direct consequence of developmental constraints. Particularly, the polysymmetry is disturbed (3a) in certain whorl in the cases of a contact between a large number of elements, and ( $3 b)$ in the entire flower, in cases of complex shape of the receptacle appearing as a mode of arrangement of a large number of elements within a whorl (mostly the gynoecium).

The case study of the order Apiales shows that it is difficult to choose a single optimal setting for the two classifications of floral symmetry, i.e., the traditional physiognomic classification (actinomorphy/zygomorphy) and the relatively recently developed geometrical classification method, based on detailed descriptions of floral morphology. An optimal classification is expected to be most useful one for descriptions of morphology, morphogenesis, and functioning. Actually, the first classification is easy to use (the type of symmetry is evident at a glance), and it reflects the patterns of biology of zoophylous flowers, but it does not give a precise idea of the structure of the flower. The second classification is not directly related to the ecological traits; it is established on the basis of a rigorously prepared floral diagram, and thus, it considers all of its structural features. However, even within this classification, flowers that are very different structurally and biologically fall within the same type of symmetry. It is noteworthy that Endress [11] does not mention the family Araliaceae in his detailed overview of floral monosymmetry and asymmetry in angiosperms. Perhaps such a divergence with our data can be explained by the complexity and ambiguity of the attribution of the flowers for many representatives of this family to a particular type of symmetry within the classification scheme 
used by Endress. The following criterion can be suggested as a basic one for the discrimination of symmetry types for cyclic flowers: (1) flowers with uniform structure of elements within each whorl vs (2) flowers with different elements within at least one whorl. This criterion is structurally accurate, easy to employ, and it reflects the functional peculiarities of a flower to a considerable extent. Within this criterion, the vast majority, if not all of the representatives of Araliaceae, possess flowers of the first type. This criterion can be used as a foundation for a novel, independent classification. We propose that our approach is widely applicable to various angiosperm groups with cyclic flowers.

In evolutionary studies of morphological characters, it is important to employ a comprehensive coding system of characters and their states that would unequivocally describe each case within the structural diversity of the lineage under examination. Given that floral symmetry is a complex and generalizing feature that represents a function of a number of features of floral morphology, we suggest that it should be split into several characters for analysis via ancestral state reconstruction and similar methods (though this would hamper investigations of correlations between characters caused, e.g., by evolutionary constraints $[97,98])$. Particularly, we find it appropriate to treat separately the symmetry of each floral whorl, the symmetry at various developmental stages (floral primordium, preanthetic bud, anthetic flower, etc.), the symmetry types resulting from interrelations between different whorls, as well as between the flower and the inflorescence axis, and also the characters listed above in each type of flower if several of them present in a species. For investigations that are focused on the ecological types of flowers, we suppose that it is efficient to use functional characters instead of strictly morphological ones, such as a type of pollen transfer, the unfixed / fixed position of a pollinator in a flower, or the orientation of a flower relative to the ground.

Author Contributions: Conceptualization, M.S.N., D.D.S. and A.A.O.; Investigation, M.S.N, D.D.S., P.V.K. and A.A.O.; Writing-Original Draft Preparation, M.S.N.; Writing-Review \& Editing, M.S.N., D.D.S. and A.A.O.; Visualization, M.S.N.; Supervision, M.S.N.; Funding Acquisition, M.S.N., D.D.S., and A.A.O. All authors have read and accepted the manuscript.

Funding: Investigation of the Vietnamese Apiales by MSN was supported by the Russian Foundation for Basic Research (project 19-54-54007). This work was carried out in accordance to a Government order for the Lomonosov Moscow State University (projects No. AAAA-A16-116021660045-2, AAAA-A16-116021660105-3). AAO was financially supported by the University of Johannesburg and the Komarov Botanical Institute (institutional research Project No. AAAA-A19-119030190018-1).

Acknowledgments: We are grateful to M.G. Pimenov for his help in the identification of our specimens of Hydrocotyle.

Conflicts of Interest: The authors declare no conflict of interest.

\section{References}

1. Chase, M.W.; Christenhusz, M.J.; Fay, M.F.; Byng, J.W.; Judd, W.S.; Soltis, D.E.; Mabberley, D.J.; Sennikov, A.N.; Soltis, P.S.; Stevens, P.F. An update of the Angiosperm Phylogeny Group classification for the orders and families of flowering plants: APG IV. Bot. J. Linn. Soc. 2016, 181, 1-20.

2. Nuraliev, M.S.; Oskolski, A.A.; Sokoloff, D.D.; Remizowa, M.V. Flowers of Araliaceae: Structural diversity, developmental and evolutionary aspects. Plant Divers. Evol. 2010, 128, 247-268. [CrossRef]

3. Nuraliev, M.S.; Sokoloff, D.D.; Oskolski, A.A. Evolutionary Floral Morphology of Araliaceae: A Case Study of the Asian Schefflera; MAKS Press: Moscow, Russia, 2017; ISBN 978-5-317-05663-6.

4. Bakker, K.; van Steenis, C.G.G.J. Pittosporaceae. In Flora Malesiana; van Steenis, C.G.G.J., Ed.; Series I: Spermatophyta; Noordhoff-Kolff N.V.: Jakarta, Indonesia, 1957; Volume 5, pp. 345-362.

5. Kårehed, J. The family Pennantiaceae and its relationships to Apiales. Bot. J. Linn. Soc. 2003, 141, 1-24. [CrossRef]

6. Sokoloff, D.D.; Karpunina, P.V.; Nuraliev, M.S.; Oskolski, A.A. Flower structure and development in Melanophylla (Torricelliaceae: Apiales): Lability in direction of corolla contortion and orientation of pseudomonomerous gynoecium in a campanulid eudicot. Bot. J. Linn. Soc. 2018, 187, 247-271.

7. Neal, P.R.; Dafni, A.; Giurfa, M. Floral symmetry and its role in plant-pollinator systems: Terminology, distribution, and hypotheses. Annu. Rev. Ecol. Syst. 1998, 29, 345-373. [CrossRef] 
8. Endress, P.K. Symmetry in flowers: Diversity and evolution. Int. J. Plant Sci. 1999, 160, S3-S23. [CrossRef] [PubMed]

9. Endress, P.K. Evolution of floral symmetry. Curr. Opin. Plant Biol. 2001, 4, 86-91. [CrossRef]

10. Endress, P.K. Angiosperm floral evolution: Morphological developmental framework. In Advances in Botanical Research; Elsevier: Amsterdam, The Netherlands, 2006; Volume 44, pp. 1-61, ISBN 978-0-12-005944-7.

11. Endress, P.K. The immense diversity of floral monosymmetry and asymmetry across angiosperms. Bot. Rev. 2012, 78, 345-397.

12. Giurfa, M.; Dafni, A.; Neal, P.R. Floral symmetry and its role in plant-pollinator systems. Int. J. Plant Sci. 1999, 160, S41-S50. [CrossRef]

13. Kalisz, S.; Ree, R.H.; Sargent, R.D. Linking floral symmetry genes to breeding system evolution. Trends Plant Sci. 2006, 11, 568-573. [CrossRef] [PubMed]

14. Jabbour, F.; Nadot, S.; Damerval, C. Evolution of floral symmetry: A state of the art. C. R. Biol. 2009, 332, 219-231. [CrossRef] [PubMed]

15. Citerne, H.; Jabbour, F.; Nadot, S.; Damerval, C. The evolution of floral symmetry. In Advances in Botanical Research; Elsevier: Amsterdam, The Netherlands, 2010; Volume 54, pp. 85-137. ISBN 978-0-12-380870-7.

16. Leins, P.; Erbar, C. Flower and Fruit: Morphology, Ontogeny, Phylogeny, Function and Ecology; Schweizerbart: Stuttgart, Germany, 2010; ISBN 978-3-510-65261-7.

17. Luo, D.; Carpenter, R.; Vincent, C.; Copsey, L.; Coen, E. Origin of floral asymmetry in Antirrhinum. Nature 1996, 383, 794-799. [CrossRef]

18. Luo, D.; Carpenter, R.; Copsey, L.; Vincent, C.; Clark, J.; Coen, E. Control of organ asymmetry in flowers of Antirrhinum. Cell 1999, 99, 367-376. [CrossRef]

19. Cubas, P.; Coen, E.; Zapater, J.M.M. Ancient asymmetries in the evolution of flowers. Curr. Biol. 2001, 11, 1050-1052. [CrossRef]

20. Jabbour, F.; Damerval, C.; Nadot, S. Evolutionary trends in the flowers of Asteridae: Is polyandry an alternative to zygomorphy? Ann. Bot. 2008, 102, 153-165. [CrossRef]

21. Fenster, C.B.; Armbruster, W.S.; Dudash, M.R. Specialization of flowers: Is floral orientation an overlooked first step? New Phytol. 2009, 183, 502-506. [CrossRef] [PubMed]

22. Giurfa, M.; Eichmann, B.; Menzel, R. Symmetry perception in an insect. Nature 1996, 382, 458-461. [CrossRef] [PubMed]

23. West, E.L.; Laverty, T.M. Effect of floral symmetry on flower choice and foraging behaviour of bumble bees. Can. J. Zool. 1998, 76, 730-739. [CrossRef]

24. Reyes, E.; Sauquet, H.; Nadot, S. Perianth symmetry changed at least 199 times in angiosperm evolution. Taxon 2016, 65, 945-964. [CrossRef]

25. Leppik, E.E. The form and function of numeral patterns in flowers. Am. J. Bot. 1956, 43, 445-455. [CrossRef]

26. Leppik, E.E. A new system for classification of flower types. Taxon 1957, 6, 64-67. [CrossRef]

27. Erbar, C.; Leins, P. Floral developmental studies in Aralia and Hedera (Araliaceae). Flora 1988, 180, $391-406$. [CrossRef]

28. Nuraliev, M.S.; Sokoloff, D.D.; Oskolski, A.A. Floral anatomy of Asian Schefflera (Araliaceae, Apiales): Comparing variation of flower groundplan and vascular patterns. Int. J. Plant Sci. 2011, 172, 735-762. [CrossRef]

29. Ronse De Craene, L.P. Floral Diagrams: An Aid to Understanding Flower Morphology and Evolution; Cambridge University Press: Cambridge, UK, 2010; ISBN 978-0-521-49346-8.

30. Philipson, W.R. Araliaceae. In Flora Malesiana; van Steenis, C.G.G.J., Ed.; Series I: Spermatophyta; Martinus Nijhoff: The Hague, The Netherlands, 1979; Volume 9, pp. 1-105.

31. Nuraliev, M.S.; Degtjareva, G.V.; Sokoloff, D.D.; Oskolski, A.A.; Samigullin, T.H.; Valiejo-Roman, C.M. Flower morphology and relationships of Schefflera subintegra (Araliaceae, Apiales): An evolutionary step towards extreme floral polymery. Bot. J. Linn. Soc. 2014, 175, 553-597. [CrossRef]

32. Sokoloff, D.D.; Oskolski, A.A.; Remizowa, M.V.; Nuraliev, M.S. Flower structure and development in Tupidanthus calyptratus (Araliaceae): An extreme case of polymery among asterids. Plant Syst. Evol. 2007, 268, 209-234. [CrossRef]

33. Ajani, Y.; Bull-Hereñu, K.; Claßen-Bockhoff, R. Patterns of flower development in Apiaceae-Apioideae. Flora 2016, 221, 38-45. [CrossRef]

34. Magin, N. Das Gynoeceum der Apiaceae-Modell und Ontogenie. Ber. Deutsch. Bot. Ges. 1977, 90, 53-66. 
35. Leins, P.; Erbar, C.; van Wyk, B.-E.; Tilney, P.M. Floral organ sequences in Apiales (Apiaceae, Araliaceae, Pittosporaceae). S. Afr. J. Bot. 2004, 70, 468-474. [CrossRef]

36. Harms, H. Araliaceae. In Die naturlichen Pflanzenfamilien; Engler, A., Prantl, K., Eds.; W. Engelmann: Leipzig, Germany, 1898; Volume 3, pp. 1-62.

37. Merrett, M.F. The breeding system of Raukaua anomalus, a small-leaved shrub from New Zealand. N. Z. J. Bot. 2005, 43, 205-210. [CrossRef]

38. Oskolski, A.A.; Sokoloff, D.D.; Van Wyk, B.-E. False paracarpy in Seemannaralia (Araliaceae): From bilocular ovary to unilocular fruit. Ann. Bot. 2010, 106, 29-36. [CrossRef] [PubMed]

39. Lowry, P.P.; Plunkett, G.M.; Oskolski, A.A. Early lineages in Apiales: Insights from morphology, wood anatomy and molecular data. Edinb. J. Bot. 2001, 58, 207-220. [CrossRef]

40. Froebe, H.A. Randmusterbildung und Synorganisation bei strahlenden Apiaceendolden. Plant Syst. Evol. 1980, 133, 223-237. [CrossRef]

41. Hart, J.M.; Henwood, M.J. A revision of Australian Trachymene (Apiaceae: Hydrocotyloideae). Aust. Syst. Bot. 2006, 19, 11-57. [CrossRef]

42. Liu, M.; Van Wyk, B.-E.; Tilney, P.M. Ontogeny of the fruits of two anomalous African woody genera, Polemanniopsis and Steganotaenia (Apiaceae), and their phylogenetic relationship. Edinb. J. Bot. 2003, 60, 249-257. [CrossRef]

43. Baumann-Bodenheim, M.G. Ableitung und Bau bicarpellatmonospermer und pseudomonocarpellater Araliaceen- und Umbelliferen-Früchte. Ber. Schweiz. Bot. Ges. 1955, 65, 481-510.

44. De Castro, O.; Colombo, P.; Gianguzzi, L.; Perrone, R. Flower and fruit structure of the endangered species Petagnaea gussonei (Sprengel) Rauschert (Saniculoideae, Apiaceae) and implications for its reproductive biology. Plant Biosyst. 2015, 149, 1042-1051. [CrossRef]

45. Karpunina, P.V.; Oskolski, A.A.; Nuraliev, M.S.; Lowry, P.P.; Degtjareva, G.V.; Samigullin, T.H.; Valiejo-Roman, C.M.; Sokoloff, D.D. Gradual vs. abrupt reduction of carpels in syncarpous gynoecia: A case study from Polyscias subg. Arthrophyllum (Araliaceae: Apiales). Am. J. Bot. 2016, 103, 2028-2057. [PubMed]

46. Wen, J. Generic delimitation of Aralia (Araliaceae). Brittonia 1993, 45, 47-55. [CrossRef]

47. Wen, J.; Plunkett, G.M.; Mitchell, A.D.; Wagstaff, S.J. The evolution of Araliaceae: A phylogenetic analysis based on ITS sequences of nuclear ribosomal DNA. Syst. Bot. 2001, 26, 144-167.

48. Shang, C.-B.; Lowry, P.P.I. Araliaceae. In Flora of China; Wu, Z., Raven, P.H., Hong, D.Y., Eds.; Science Press: Beijing, China; Missouri Botanical Garden: St. Louis, MO, USA, 2007; Volume 13, pp. 435-491.

49. Drude, O. Umbelliferae. In Die naturlichen Pflanzenfamilien; Engler, A., Prantl, K., Eds.; W. Engelmann: Leipzig, Germany, 1898; Volume 3, pp. 63-250.

50. Narayana, L.L.; Radhakrishnaiah, M. Floral anatomy of Pittosporaceae: Five species of Pittosporum. Can. J. Bot. 1982, 60, 1859-1867. [CrossRef]

51. Zhou, Q.; Fu, D.; Jin, X. Floral morphology and anatomy of Pittosporum tobira (Pittosporaceae). Nord. J. Bot. 2005, 23, 345-352. [CrossRef]

52. Erbar, C.; Leins, P. An analysis of the early floral development of Pittosporum tobira (Thunb.) Aiton and some remarks on the systematic position of the family Pittosporaceae. Feddes Repertorium 1995, 106, 463-473. [CrossRef]

53. Cufodontis, G. Pittosporum in Aethiopien: Vorarbeit zu einer Revision der afrikanischen Arten. Österreichische Botanische Zeitschrift 1951, 98, 105-137. [CrossRef]

54. Haas, J.E. The Pacific species of Pittosporum Banks ex Gaertn. (Pittosporaceae). Allertonia 1977, 1, $73-167$.

55. Friis, I. A Reconsideration of Pittosporum in Africa and Arabia. Kew Bull. 1987, 42, 319-335. [CrossRef]

56. Judd, W.S. The Pittosporaceae in the southeastern United States. Harv. Pap. Bot. 1996, 1, 15-26.

57. Prenner, G.; Bateman, R.M.; Rudall, P.J. Floral formulae updated for routine inclusion in formal taxonomic descriptions. Taxon 2010, 59, 241-250. [CrossRef]

58. Schoute, J.C. On corolla aestivation and phyllotaxis of floral phyllomes. Verhandeling der Koninklijke Akademie van Wetenschappen te Amsterdam Afdeeling Natuurkunde 1935, 34, 1-77.

59. Kaden, N.N.; Urmantzev, Y.A. Isomery in live nature. II. Results of investigations. Botanichesky Zhurnal 1971, 56, 161-174. 
60. Sokoloff, D.D.; Remizowa, M.V.; Timonin, A.C.; Oskolski, A.A.; Nuraliev, M.S. Types of organ fusion in Angiosperm flowers (with examples from Chloranthaceae, Araliaceae and monocots). Biol. Serb. 2018, $40,16-46$.

61. Nuraliev, M.S.; Beer, A.S.; Oskolski, A.A. Vascular anatomy of flower of Tupidanthus and related species of Schefflera and the origin of floral polymery in Araliaceae. Botanichesky Zhurnal 2009, 94, 1-18.

62. Henslow, G. On the vascular systems of floral organs, and their importance in the interpretation of the morphology of flowers. J. Linn. Soc. Lond. Bot. 1890, 28, 151-197. [CrossRef]

63. Jackson, G. A study of the carpophore of the Umbelliferae. Am. J. Bot. 1933, 20, 121-144. [CrossRef]

64. Theobald, W.L. Venation pattern and fruit development in Lomatium dasycarpum (Umbelliferae). Ann. Bot. 1967, 31, 255-262. [CrossRef]

65. Magin, N. Eine blütenmorphologische Analyse der Lagoecieae (Apiaceae). Plant Syst. Evol. 1980, 133, 239-259. [CrossRef]

66. Liu, M.; Plunkett, G.M.; Lowry, P.P.; Wyk, B.-E.V.; Tilney, P.M. The taxonomic value of fruit wing types in the order Apiales. Am. J. Bot. 2006, 93, 1357-1368. [CrossRef]

67. Perkins, A.J. Hydrocotyle spinulifera and H. dimorphocarpa (Araliaceae), two new Western Australian species with dimorphic mericarps. Nuytsia 2018, 29, 57-65.

68. Konstantinova, A.I. The systematic position of Uldinia ceratocarpa (Trachymene ceratocarpa) in the order Apiales based on the analysis of comparative carpological data. Bull. Mosc. Soc. Nat. Biol. Ser. 2015, 120, 38-48.

69. Bukhari, G.; Zhang, J.; Stevens, P.F.; Zhang, W. Evolution of the process underlying floral zygomorphy development in pentapetalous angiosperms. Am. J. Bot. 2017, 104, 1846-1856. [CrossRef]

70. Zhang, Z.; Zhang, H.; Chang, H.; Turland, N.J. Pittosporaceae. In Flora of China; Wu, Z., Raven, P.H., Eds.; Science Press: Beijing, China; Missouri Botanical Garden: St. Louis, MO, USA, 2003; Volume 9, pp. 1-17.

71. Karpunina, P.V.; Nuraliev, M.S.; Oskolski, A.A.; Sokoloff, D.D. Transference of positional information from bracteoles and sepals to petals in species with labile handedness of contort corolla: Mechanical forces or prepatterning? In Asymmetry in Plants: Biology of Handedness; Bahadur, B., Krishnamurthy, K.V., Ghose, M., Adams, S.J., Eds.; CRC Press: Boca Raton, FL, USA, 2019; pp. 285-300. ISBN 978-1-138-58794-6.

72. Philipson, W.R.; Stone, B.C. The systematic position of Aralidium Miq.-A multidisciplinary study. 1. Introduction and floral and general anatomy. Taxon 1980, 29, 391-403. [CrossRef]

73. Plunkett, G.M.; Wen, J.; Lowry, P.P., II. Infrafamilial classifications and characters in Araliaceae: Insights from the phylogenetic analysis of nuclear (ITS) and plastid (trnL-trnF) sequence data. Plant Syst. Evol. 2004, 245, 1-39. [CrossRef]

74. Jebb, M.H.P. A revision of the genus Trevesia (Araliaceae). Glasra 1998, 3, 85-113.

75. Erbar, C.; Leins, P. Different patterns of floral development in whorled flowers, exemplified by Apiaceae and Brassicaceae. Int. J. Plant Sci. 1997, 158, S49-S64. [CrossRef]

76. Erbar, C.; Leins, P. Sympetaly in Apiales (Apiaceae, Araliaceae, Pittosporaceae). S. Afr. J. Bot. 2004, 70, 458-467. [CrossRef]

77. Philipson, W.R. Constant and variable features of the Araliaceae. Bot. J. Linn. Soc. 1970, 63 (Suppl. 1), 87-100.

78. Takhtajan, A. Flowering Plants; Springer: Dordrecht, The Netherlands, 2009; ISBN 978-1-4020-9608-2.

79. Endress, P.K. Flower structure and trends of evolution in eudicots and their major subclades. Ann. Mo. Bot. Gard. 2010, 97, 541-583. [CrossRef]

80. Ushimaru, A.; Hyodo, F. Why do bilaterally symmetrical flowers orient vertically? Flower orientation influences pollinator landing behaviour. Evol. Ecol. Res. 2005, 7, 151-160.

81. Ushimaru, A.; Dohzono, I.; Takami, Y.; Hyodo, F. Flower orientation enhances pollen transfer in bilaterally symmetrical flowers. Oecologia 2009, 160, 667-674. [CrossRef] [PubMed]

82. Alexeev, D.V.; Ezhova, T.A.; Kozlov, V.N.; Kudryavtsev, V.B.; Nosov, M.V.; Penin, A.A.; Skryabin, K.G.; Choob, V.V.; Shulga, O.A.; Shestakov, S.V. Spatial pattern formation in the flower of Arabidopsis thaliana: Mathematical modeling. Dokl. Biol. Sci. 2005, 401, 133-135. [CrossRef]

83. Rudall, P.J. All in a spin: Centrifugal organ formation and floral patterning. Curr. Opin. Plant Biol. 2010, 13, 108-114. [CrossRef] [PubMed]

84. Penin, A.A.; Logacheva, M.D. Correlation between number and position of floral organs in Arabidopsis. Ann. Bot. 2011, 108, 123-131. [CrossRef]

85. Endress, P.K. Syncarpy and alternative modes of escaping disadvantages of apocarpy in primitive angiosperms. Taxon 1982, 31, 48-52. [CrossRef] 
86. Armbruster, W.S.; Debevec, E.M.; Willson, M.F. Evolution of syncarpy in angiosperms: Theoretical and phylogenetic analyses of the effects of carpel fusion on offspring quantity and quality: Evolution of syncarpy. J. Evol. Biol. 2002, 15, 657-672. [CrossRef]

87. Endress, P.K. Multicarpellate gynoecia in angiosperms: Occurrence, development, organization and architectural constraints. Bot. J. Linn. Soc. 2014, 174, 1-43. [CrossRef]

88. Ronse De Craene, L. Understanding the role of floral development in the evolution of angiosperm flowers: Clarifications from a historical and physico-dynamic perspective. J. Plant Res. 2018, 131, 367-393. [CrossRef]

89. Tucker, S.C. Evolutionary lability of symmetry in early floral development. Int. J. Plant Sci. 1999, 160, S25-S39. [CrossRef]

90. Faegri, K.; Van Der Pijl, L. The Principles of Pollination Ecology; Pergamon Press: Oxford, UK, 1966; ISBN 978-0-08-016421-2.

91. Ronse De Craene, L.P.; Smets, E.F. Merosity in flowers: Definition, origin, and taxonomic significance. Plant Syst. Evol. 1994, 191, 83-104. [CrossRef]

92. Sokoloff, D.D.; Nuraliev, M.S.; Oskolski, A.A.; Remizowa, M.V. Gynoecium evolution in angiosperms: Monomery, pseudomonomery, and mixomery. Mosc. Univ. Biol. Sci. Bull. 2017, 72, 97-108. [CrossRef]

93. Zhang, J.; Stevens, P.F.; Zhang, W. Evolution of floral zygomorphy in androecium and corolla in Solanaceae. J. Syst. Evol. 2017, 55, 581-590. [CrossRef]

94. Madrigal, Y.; Alzate, J.F.; González, F.; Pabón-Mora, N. Evolution of RADIALIS and DIVARICATA gene lineages in flowering plants with an expanded sampling in non-core eudicots. Am. J. Bot. 2019, 106, 334-351. [CrossRef]

95. Clark, J.I.; Coen, E.S. The cycloidea gene can respond to a common dorsoventral prepattern in Antirrhinum. Plant J. 2002, 30, 639-648. [CrossRef] [PubMed]

96. Damerval, C.; Guilloux, M.L.; Jager, M.; Charon, C. Diversity and evolution of CYCLOIDEA-like TCP genes in relation to flower development in Papaveraceae. Plant Physiol. 2007, 143, 759-772. [CrossRef] [PubMed]

97. Sauquet, H.; von Balthazar, M.; Magallón, S.; Doyle, J.A.; Endress, P.K.; Bailes, E.J.; Barroso de Morais, E.; Bull-Hereñu, K.; Carrive, L.; Chartier, M.; et al. The ancestral flower of angiosperms and its early diversification. Nat. Commun. 2017, 8, 16047. [CrossRef] [PubMed]

98. Sokoloff, D.D.; Remizowa, M.V.; Bateman, R.M.; Rudall, P.J. Was the ancestral angiosperm flower whorled throughout? Am. J. Bot. 2018, 105, 5-15. [CrossRef] 